DR. ANNE HEIKKINEN (Orcid ID : 0000-0001-9852-773X)

Article type : Research Report

\title{
CORRECT EXPRESSION AND LOCALIZATION OF COLLAGEN XIII IS CRUCIAL FOR THE NORMAL FORMATION AND FUNCTION OF THE NEUROMUSCULAR SYSTEM
}

Heli Härönen ${ }^{1}$, Zarin Zainul ${ }^{1}$, Nikolay Naumenko ${ }^{2}$, Raija Sormunen ${ }^{3}$, Ilkka Miinalainen ${ }^{3}$, Anastasia Shakirzyanova ${ }^{4,5}$, Sabrina Santoleri ${ }^{1}$, Antti V. Kemppainen ${ }^{1}$, Rashid Giniatullin ${ }^{4,5}$, Taina Pihlajaniemi ${ }^{1}$, Anne Heikkinen ${ }^{1}$

1. Center for Cell-Matrix Research, Biocenter Oulu, Faculty of Biochemistry and Molecular Medicine, P.O.Box 5400, 90014 University of Oulu, Oulu, Finland

2. Department of Biotechnology and Molecular Medicine, A. I. Virtanen Institute for Molecular Sciences, University of Eastern Finland, P.O.Box 1627, 70211 Kuopio, Finland

3. Biocenter Oulu Electron Microscopy Core Facility, P.O.Box 5000, 90014 University of Oulu, Oulu, Finland

4. Department of Neurobiology, A. I. Virtanen Institute for Molecular Sciences, University of Eastern Finland, P.O.Box 1627, 70211 Kuopio, Finland

5. Laboratory of Neurobiology, Department of Physiology, Kazan Federal University, Kremlyovskaya Street 18, 420008 Kazan, Russia

This article has been accepted for publication and undergone full peer review but has not been through the copyediting, typesetting, pagination and proofreading process, which may lead to differences between this version and the Version of Record. Please cite this article as doi: 10.1111/ejn.14346

This article is protected by copyright. All rights reserved. 
Correspondence: Heikkinen Anne, anne.heikkinen@oulu.fi, +358-(0)294 485807, Center for Cell-Matrix Research, Biocenter Oulu, Faculty of Biochemistry and Molecular Medicine, P.O.Box 5400, 90014 University of Oulu, Oulu, Finland

A running title: Correct collagen XIII expression crucial for the NMJ

Keywords: collagen XIII, genetically modified mice, neuromuscular junction, skeletal muscle, overexpression

\section{ABSTRACT}

Transmembrane collagen XIII has been linked to maturation of the musculoskeletal system. Its absence in mice $\left(\mathrm{Coll}_{3} \mathrm{al}^{-/}\right)$results in impaired neuromuscular junction (NMJ) differentiation and function, while transgenic overexpression $\left(C o l 13 a 1^{\text {oe }}\right)$ leads to abnormally high bone mass. Similarly, loss-of-function mutations in COL13A1 in man produce muscle weakness, decreased motor synapse function and mild dysmorphic skeletal features. Here analysis of the exogenous overexpression of collagen XIII in various muscles revealed highly increased transcript and protein levels, especially in the diaphragm. Unexpectedly, the main location of exogenous collagen XIII in the muscle was extrasynaptic, in fibroblast-like cells, while some motor synapses were devoid of collagen XIII, possibly due to a dominant negative effect. Concomitantly, phenotypical changes in the NMJs of the Coll3al ${ }^{\text {oe }}$ mice partly resembled those previously observed in $\mathrm{Col}_{13} \mathrm{al} \mathrm{I}^{-/-}$mice. Namely, the overall increase in collagen XIII expression in the muscle produced both pre- and postsynaptic abnormalities at the NMJ, especially in the diaphragm. We discovered delayed and compromised acetylcholine receptor (AChR) clustering, axonal neurofilament aggregation, patchy acetylcholine vesicle (AChV) accumulation, disrupted adhesion of the nerve and muscle, 
Schwann cell invagination and altered evoked synaptic function. Furthermore, the patterns of the nerve trunks and AChR clusters in the diaphragm were broader in the adult muscles, and already prenatally in the Coll3al ${ }^{\text {oe }}$ mice, suggesting collagen XIII involvement in the development of the neuromuscular system. Overall, these results confirm the role of collagen XIII at the neuromuscular synapses and highlight the importance of its correct expression and localization for motor synapse formation and function.

\section{INTRODUCTION}

Neuromuscular junctions (NMJ), cholinergic peripheral synapses between Schwann cellwrapped (ShC) presynaptic motor neurons and postsynaptic skeletal muscle fibers, pass contraction signals from the central nervous system to the muscles. Thus their proper formation, maturation, stability and function are crucial for vital processes such as muscle movements and breathing. A repertoire of presynaptic, synaptic and postsynaptic molecules control this synaptic machinery and enable delicate and precise cross-talk between the central nervous system and the muscles, so that loss or compromised outcome of this system can have consequences varying from mild muscle weakness to lethality (Souza et al., 2016). Collagen XIII, a muscle-derived transmembrane protein, has been identified as a postsynaptic/synaptic NMJ component affecting their structure and function as well as postinjury regeneration (Härönen et al., 2017; Latvanlehto et al., 2010; Zainul et al., 2018). Mouse studies have indicated delayed postsynaptic maturation, impaired acetylcholine vesicle (AChV) accumulation, compromised nerve-muscle adhesion, and most importantly, compromised function of the NMJs in the absence of collagen XIII (Latvanlehto et al., 2010). The loss of NMJ function has been shown recently to result in congenital myasthenic syndrome type 19 (CMS19) in humans (Logan et al., 2015). Muscle weakness starting soon after birth is characteristic of CMS19 patients. 
Collagen XIII is a non-fibrillar, homotrimeric type II transmembrane protein having an Nterminal intracellular domain, a hydrophobic transmembrane domain and a large (150nmlong) extracellular C-terminal domain (Hägg et al., 1998; Tu et al., 2002). At NMJs it is synaptically located on the sarcolemma and adjacent basement membrane (BM) of both fast and slow-twitch muscle fibers (Härönen et al., 2017; Latvanlehto et al., 2010). Its ectodomain can be cleaved from the plasma membrane or the trans-Golgi network by proteinases of the furin family to become a soluble protein (Väisänen et al., 2004), the resulting ectodomain having been proved to interact in vitro with extracellular matrix (ECM) components such as fibronectin, cellular receptors such as the integrin $\alpha 1$ subunit and also the BM components perlecan and nidogen-2 (Tu et al., 2002). The latter three molecules are also NMJ components (Arikawa-Hirasawa et al., 2002; Fox et al., 2008; Martin et al., 1996). Perlecan is concentrated in the synaptic BM and its deficiency in mice leads to lethal respiratory failure soon after birth (Arikawa-Hirasawa et al., 2002). Embryonal studies have indicated a loss of the collagen-like tail, collagen Q (ColQ), of acetylcholinesterase (AChE), or of AChE itself, from the NMJs of perlecan-null embryos (Arikawa-Hirasawa et al., 2002), a situation indicative of interaction between ColQ and perlecan, as shown in vitro (Peng et al., 1999). Interestingly, the development of the perlecan-null NMJs was otherwise normal (ArikawaHirasawa et al., 2002). Nidogen-2 is also located at the synaptic BM and its deficiency in mice leads to a defect in postsynaptic maturation, manifested as immature and fragmented acetylcholine receptor $(\mathrm{AChR})$ clusters from 8 weeks of age onwards and persisting until adulthood (Fox et al., 2008). Another binding partner of collagen XIII, the integrin $\alpha 1$ subunit, has been localized to preterminal structures, possibly in both terminal ShCs and preterminal motor neurons (Martin et al., 1996), but its function at the NMJ remains unknown.

This article is protected by copyright. All rights reserved. 
The connective tissue of adult muscles consists of a small number of fibroblasts embedded in the ECM that surrounds the individual muscle fibers, muscle fiber bundles and whole anatomical muscles (Gillies and Lieber, 2011). In contrast, the developing embryonal connective tissue in muscles harbors a large number of fibroblasts surrounded by relatively little ECM (Mathew et al., 2011). It is known that connective tissue and muscles are tightly coordinated both temporally and spatially in terms of their development. To broaden our knowledge of collagen XIII in the formation and maturation of the neuromuscular system, we studied the gross anatomy, function and morphology of the neuromuscular unit in transgenic mice overexpressing collagen XIII $\left(\mathrm{Coll}_{3} \mathrm{al}^{\mathrm{oe}}\right)$, in which osteoblastic collagen XIII overexpression provides them with a proliferative advantage and excess bone formation is clearly seen from the age of 3 to 4 weeks onwards (Ylönen et al., 2005). Information on collagen XIII expression and its effects on the NMJ and muscles of these mice was nevertheless lacking. Collagen XIII was found to be overexpressed in the muscles of these

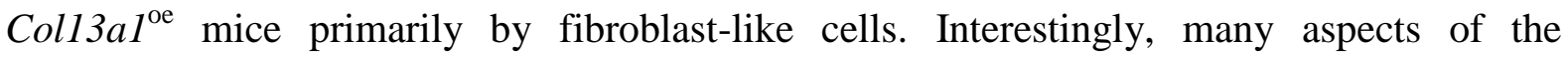
maturation, morphology and function of the NMJs were impaired in these mice even though the majority of the collagen XIII overexpression was found to be extrasynaptic. The data highlight the importance of correct collagen XIII expression for the formation and function of the neuromuscular system.

\section{MATERIALS AND METHODS}

\section{Mouse lines and maintenance}

Detailed information on the generation of the transgenic Coll3al ${ }^{\text {oe }}$ (Ylönen et al., 2005) and knock-out Coll3al ${ }^{-/-}$mice (Latvanlehto et al., 2010; Ylönen et al., 2005) has been published previously. The mouse lines are publicly available in the Infrafrontier EMMA repository 
(https://www.infrafrontier.eu/infrafrontier-research-infrastructure/organisation/europeanmouse-mutant-archive) as B6.Cg-Tg(Col13a1)2Pih/Oulu (EM:09885) and B6.129Col13a1 $^{\text {tm3.1Pih } / O u l u ~(E M: 09878), ~ r e s p e c t i v e l y . ~ C 57 B L / 6 J-b a c k ~ c r o s s e d ~ m i c e ~ o f ~ b o t h ~ s e x e s ~}$ were used in the experiments and wild-type littermates were used as controls. For this purpose, transgene-positive Coll3al ${ }^{\mathrm{oe}}$ males were bred with $\mathrm{C} 57 \mathrm{BL} / 6 \mathrm{~J}$ females and heterozygous Coll3al ${ }^{+/-}$mice with each other. Mice were housed in the University of Oulu specific pathogen free (SPF) Animal Facility at $+21^{\circ} \mathrm{C}$ on Tapvei aspen bedding with a 12hour light/dark cycle, multicaged whenever possible and fed with Teklad global 18\% protein rodent diet with free access to food and water. Permission for the maintenance of the mouse models and conducting of the animal experiments was obtained from the Finnish Animal Care and Use Committee (ESAVI/4220/04.10.07/2013). All the mouse experiments complied with the European Community Council Directive on the protection of animals used for scientific purposes (September 22, 2010; 2010/63/EEC), national legislation and the regulations for the care and use of laboratory animals. Mice were euthanized in their home cages, whenever possible, using a standard procedure with $\mathrm{CO}_{2}$ during the office hours either in the Animal Facility or Faculty facilities authorized for laboratory animal work. The total number of animals used in the study was 131 and groups were not purposely enlarged to obtain/increase statistical significance.

\section{Tissue transcript and protein level analyses}

For the analyses of collagen XIII protein levels the diaphragm, soleus and extensor digitorum longus (EDL) muscles were dissected from 12-week-old wild-type, Coll3al ${ }^{\mathrm{oe}}$ and Coll3a1 ${ }^{-/-}$ mice (3;2;1 animals per group, respectively) and whole tissue proteins were extracted using a Tri Reagent system (Sigma-Aldrich). The proteins were run in $8 \%$ reduced SDS-PAGE gels and blotted with a rabbit anti-mouse collagen XIII antibody (ColXIII (Kvist et al., 2001), 
1:333). A mouse anti-GAPDH (Abcam, 1:1000) antibody was used as the loading control. For detection, horseradish peroxidase-conjugated goat anti-rabbit and goat anti-mouse secondary antibodies (1:5000 both) in conjunction with Pierce ${ }^{\mathrm{TM}}$ ECL Western Blotting Substrates (Thermo Fisher Scientific). The amount of collagen XIII protein was calculated using Western blot band intensities normalized by reference to the loading control. The intensity calculations were performed using the ImageJ $1.48 \mathrm{~V}$ free image-processing and analysis software (Wayne Rasband, National Institute of Health, USA).

Total RNA was extracted from the diaphragm, soleus and EDL muscles of 12-week-old wild-

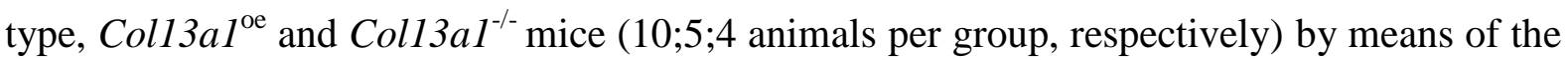
Tri Reagent system (Sigma-Aldrich) and used for reverse transcription with the iScript ${ }^{\mathrm{tm}}$ cDNA Synthesis Kit (Bio-Rad) and RT-qPCR using the $\mathrm{iTaq}^{\mathrm{tm}}$ Universal SYBR $^{\circledR}$ Green Supermix kit (Bio-Rad) according to the manufacturers' protocols. The primers 5'-GAA GCC CCG AAG ATG TCT CC-3' in exon two and 5'-TGG GAG TCC AGG TCT TCC AG-3' in exon four were used to detect Coll3al transcripts, and primers 5'-AGG TCG GTG TGA ACG GAT TTG-3' and 5'-TGT AGA CCA TGT AGT TGA GGT CA-3' to amplify the GAPDH transcripts (PrimerBank ID 6679937a1;

https://pga.mgh.harvard.edu/primerbank/index.html (Spandidos et al., 2008; Spandidos et al., 2010; X. Wang and Seed, 2003)) as an internal control.

\section{Histochemistry and morphometric analyses}

Muscles from 12-week-old wild-type and $\operatorname{Coll}_{3} a l^{\mathrm{oe}}$ mice (4 animals per group) were weighed, mounted in Tissue-Tek medium (Sakura) and frozen in iso-pentane cooled with liquid nitrogen. $5 \mu \mathrm{m}$ sections were cut and stained with hematoxylin and eosin and imaged 
using a Leica Histology Microscope. The muscle fiber area was determined from sagittal sections using Image J $1.48 \mathrm{~V}$ software.

\section{Whole mount immunofluorescent stainings}

For the whole mount immunostainings muscles from 12-week-old wild-type, Coll $3 a 1^{\mathrm{oe}}$ and

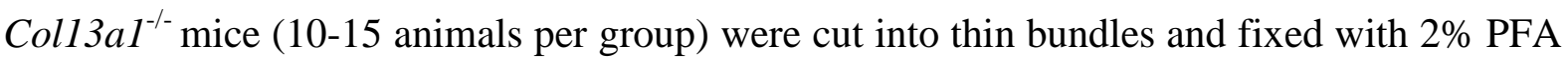
for 10 min at RT. Alternatively, whole diaphragm muscle from 12-week-old (6-7 animals per group) or 17.5 embryonic day (E) (3 embryos per group) wild-type and Coll $3 a 1^{\text {oe }}$ mice were stained intact. After rinsing with PBS, the samples were permeabilized with PBS-1\% Triton $\mathrm{X}-100 \mathrm{o} / \mathrm{n}$ at $+4^{\circ} \mathrm{C}$. To block free PFA, the samples were neutralized with $100 \mathrm{mM}$ glycine/PBS for $15 \mathrm{~min}$ at RT, after which they were blocked with $2.5 \% \mathrm{FBS}, 2.5 \%$ BSA/PBS- $0.1 \%$ Triton X-100 o/n at $+4^{\circ} \mathrm{C}$. Primary antibodies diluted in blocking buffer were incubated with samples o/n or over two nights at $+4^{\circ} \mathrm{C}$. The primary antibodies used were rabbit anti-neurofilament H, (NF; Millipore, Cat\# AB1991, RRID:AB_91203, 1:800), mouse monoclonal anti-synaptotagmin 2 (Syt-2; Developmental studies hybridoma bank, Cat\# znp-1, RRID:AB_531910, 1:100), rabbit anti-mouse collagen XIII (ColXIII/NC3 (Kvist et al., 2001) 1:400), rabbit anti-S100 (Agilent Technologies, Cat\# Z0311, RRID:AB_10013383, 1:100), guinea pig anti-Ca2+ channel P/Q-type, $\alpha$-1A subunit (VDCC, Synaptic Systems, Cat\# 152 205, RRID:AB_2619842, 1:300), mouse monoclonal antiskeletal myosin fast (fMHC, Sigma-Aldrich, Cat\# M4276, RRID:AB_477190, 1:400), rabbit anti-HA-probe (Santa Cruz Biotechnology, Cat\# sc-805, RRID:AB_631618, 1:100), mouse monoclonal anti- $\alpha$ smooth muscle actin ( $\alpha$-SMA, Sigma-Aldrich, Cat\# A2547, RRID:AB_476701, 1:200) and rat anti-mouse CD31 (PECAM-1; BD Biosciences, Cat\# 550274, RRID:AB_393571, 1:100) antibodies. After washing with blocking buffer, the samples were incubated with $\mathrm{CF}^{\mathrm{TM}} 405 \mathrm{~S}$, Alexa Fluor ${ }^{\circledR}$ 488, Alexa Fluor ${ }^{\circledR}$ 594-conjugated 
$\alpha$-Bungarotoxin ( $\alpha$-BTX; Biotium and Molecular Probes, Invitrogen, 1:1000) or Fasciculin II (FascII; Latoxan, 1:100) conjugated in-house with Alexa Fluor ${ }^{\circledR} 488$ 5-SDP ester (Invitrogen), in combination with Alexa Fluor 405, 488, 568 or 594-conjugated (Molecular Probes, Invitrogen, 1:300) secondary antibodies o/n at $+4^{\circ} \mathrm{C}$. All incubations were performed in rotation. After staining, the muscles were washed with PBS and mounted on glass microscope slides with Thermo Scientific ${ }^{\mathrm{TM}}$ Shandon ${ }^{\mathrm{TM}}$ Immu-Mount ${ }^{\mathrm{TM}}$ (Fisher Scientific) anti-bleaching reagent.

For the postsynaptic maturation and AChR cluster pattern analyses, diaphragm muscles from wild-type and Coll3al ${ }^{\mathrm{oe}}$ mice were collected at embryonic day (E) 17.5, birth, and 2, 4, 8, 12 and 25 weeks of age (2-3 animals per group; only those collected at 12 weeks were used for NMJ pattern analysis, 7 animals per group), fixed with $4 \%$ PFA o/n at $+4^{\circ} \mathrm{C}$ and washed with PBS. After blocking with $2.5 \%$ FBS, $2.5 \%$ BSA/PBS- $0.1 \%$ Triton X-100 o/n at $+4^{\circ} \mathrm{C}$, the samples were stained with Alexa Fluor ${ }^{\circledR}$ 594-conjugated $\alpha$-BTX in blocking buffer o/n at $+4^{\circ} \mathrm{C}$. After washing with PBS, the muscles were mounted on glass microscope slides with Thermo Scientific ${ }^{\mathrm{TM}}$ Shandon ${ }^{\mathrm{TM}}$ Immu-Mount ${ }^{\mathrm{TM}}$ (Fisher Scientific) anti-bleaching reagent. The immunostainings were imaged using an Olympus FV1000 scanning confocal microscope, a Zeiss Cell Observer spinning disc confocal microscope or a Zeiss LSM 780 laser scanning confocal microscope provided by the Biocenter Oulu Light Microscopy Core Facility and the sizes and fragmentations of the NMJs were analyzed with the ImageJ $1.48 \mathrm{~V}$ software. Terminal divisions, branches and tips were manually calculated utilizing neurofilament staining as shown in Fig. 5D and previously (Härönen et al., 2017). The samples were analyzed blinded for the genotype.

This article is protected by copyright. All rights reserved. 


\section{Histochemical detection of AChE and NMJ pattern analysis}

For the overall nerve pattern analysis, diaphragm muscles were collected from 12-week-old wild-type and Coll3al ${ }^{\text {oe }}$ mice (4 animals per group) and freshly imaged with a Leica Microsystems microscope and analyzed with ImageJ 1.48Vsoftware. For the histochemical detection of $\mathrm{AChE}$, the diaphragm muscles were further freshly incubated with a staining solution containing $5 \mathrm{mM}$ acetylthiocholine iodide, $40 \mathrm{mM}$ glycine and $8 \mathrm{mM} \mathrm{CuSO}_{4}$ (added last and slowly to prevent precipitation)/120 mM phosphate buffer, $\mathrm{pH} 6.4$ (Karnowsky and Roots, 1964). After a 1-hour incubation at RT, the samples were mounted on glass microscope slides with Thermo Scientific ${ }^{\mathrm{TM}}$ Shandon $^{\mathrm{TM}}$ Immu-Mount ${ }^{\mathrm{TM}}$ (Fisher Scientific) anti-bleaching reagent, imaged with a Leica Microsystems microscope and analyzed blinded for the genotype with ImageJ $1.48 \mathrm{~V}$ software.

\section{Ultrastructural analyses}

$1 \mathrm{x} 1 \mathrm{~mm}$ pieces of diaphragm muscle from NMJ-rich areas from 12-week-old wild-type and

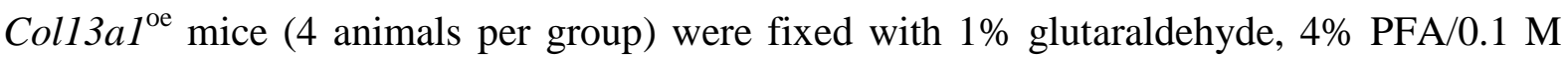
phosphate buffer, $\mathrm{pH} 7.3 \mathrm{o} / \mathrm{n}$ at $+4^{\circ} \mathrm{C}$, after which they were postfixed with $1 \%$ osmium tetroxide, dehydrated in acetone and embedded in Epon LX112. Thin sections of these NMJrich areas were prepared and analyzed with a Tecnai G2 Spirit $120 \mathrm{kV}$ transmission electron microscope (TEM) using Veleta and Quemesa CCD cameras and a Philips CM100 TEM equipped with a CCD camera provided by the Biocenter Oulu Elelctron Microscopy Core Facility. To evaluate the nerve terminal $\mathrm{AChV}$ density, electron micrographs were exploited in measuring the nerve terminal area (in $\mu \mathrm{m}^{2}$ ) and number of AChVs in the corresponding area. To analyze the AZ frequency, length of the preterminal membrane facing the synaptic cleft was measured and number of AZs in the corresponding measure was calculated. The images were analyzed blinded for the genotype. Image J $1.48 \mathrm{~V}$ software was utilized in the analyses.

This article is protected by copyright. All rights reserved. 


\section{Electrophysiological measurements ex vivo}

Electrophysiological recordings were made from diaphragm muscles ex vivo at RT. Wildtype and Coll3al ${ }^{\text {oe }}$ mice of both sexes (9-10 animals per group) at 4 to 5 months of age were euthanized and their diaphragms immediately dissected into 2-4 muscle strips, which were then placed in an organic glass chamber $(3.5-\mathrm{ml})$ with the bottom covered with Sylgard (World Precision Instruments). For recording of the evoked potentials, the left phrenic nerves (14-16 $\mathrm{mm}$ in length) were dissected together with the diaphragm. 4-12 synapses were sampled in each diaphragmal strip.

All the solutions were applied to the muscle via a superfusion system at a rate of $2 \mathrm{ml} / \mathrm{min}$. Physiological Krebs' solution contained $120 \mathrm{mM} \mathrm{NaCl}, 5 \mathrm{mM} \mathrm{KCl}, 2 \mathrm{mM} \mathrm{CaCl}, 1 \mathrm{mM}$ $\mathrm{MgCl}_{2}, 11 \mathrm{mM}$ glucose, $1 \mathrm{mM}$ NaHPO4 and $24 \mathrm{mM} \mathrm{NaHCO}_{3}$ (gassed with $95 \% \mathrm{O}_{2}, 5 \%$ $\mathrm{CO}_{2}$ ). All the solutions were adjusted to $\mathrm{pH}$ 7.4. To prevent muscle contractions in the experiments with motor nerve stimulation, the diaphragms were incubated in $1 \mu \mathrm{M} \mu$ conotoxin (Sigma-Aldrich) for 30-35 min before the experiment (Hong and Chang, 1993).

To evaluate the readily releasable pool (RRP) of transmitter in the nerve terminals, we used a hypertonic sucrose solution (Kashani et al., 2001; Virmani et al., 2005), making the recordings in the sucrose test at 5-10 min intervals in the sustain phase of stimulated release induced by a bath application of $500 \mathrm{mM}$ sucrose (Sara et al., 2002). $1 \mu \mathrm{M}$ tetrodotoxin (TTX; Ascent Scientific) was present throughout each of these experiments to prevent excessive activity and generation of spontaneous action potentials.

This article is protected by copyright. All rights reserved. 
The endplate potentials (EPPs) and spontaneous miniature endplate potentials (MEPPs) evoked by diaphragmal nerve stimulation were recorded using a custom-made low-noise amplifier and standard microelectrodes (8-15 $\mathrm{M} \Omega$ electrode resistance when filled with $3 \mathrm{M}$ $\mathrm{KCl})$ typically for a period of $2 \mathrm{~min}(10-20 \mathrm{~s}$ in the sucrose test). Only synapses with a fall in membrane potential not more than $5 \mathrm{mV}$ during the observation period were taken into consideration.

The EPPs were induced by suprathreshold stimulation of the phrenic nerve via a suction electrode connected to an isolated pulse stimulator Model 2100 (A-M Systems). EPPs and MEPPs (recorded at a membrane potential of $\sim 70-72 \mathrm{mV}$ ) digitized at $50 \mathrm{kHz}$ were recorded using a low-noise custom-made amplifier, stored in a PC using an NI PCI6221 data acquisition board (National Instruments) and visualized with the WinEDR V3.0.4 software (Strathclyde University, Glasgow, Scotland, UK). The amplitudes of the EPPs and MEPPs and inter-event intervals of the MEPPs were analyzed off-line with the WinEDR V3.0.4 and ClampFit V10.2.0.14 (Molecular Devices) software.

\section{Statistical analyses}

Normality in the data was evaluated using the Kolmogorov-Smirnov test, and the statistical significance of normally distributed data was calculated with the unpaired, two-tailed t-test, and that of non-parametric data, or data from too small a number of samples for evaluating normality, with the Mann-Whitney test. The statistical analyses were performed using the Prism (GraphPad Software, Inc.) and Origin graphic software (v.8.0, OriginLab Corp.). All data are presented as means \pm SD calculated per mouse, unless otherwise stated. Statistically significant differences are indicated as $* \mathrm{p}<0.05, * * \mathrm{p}<0.01$ and $* * * \mathrm{p}<0.001$. 


\section{RESULTS}

\section{Collagen XIII is overexpressed in the muscles of $\mathrm{Coll3a1}^{\mathrm{oe}}$ mice}

We have previously found collagen XIII overexpression in Coll3al ${ }^{\mathrm{oe}}$ mice to result in massive bone overgrowth. Furthermore, the muscles of these mice were shown to overexpress collagen XIII, but the muscle and NMJ phenotypes were not studied. Overexpression of collagen XIII in Coll3al ${ }^{\mathrm{oe}}$ mice was achieved by random insertion of a collagen XIII cDNA driven by a $\sim 1-\mathrm{kb}$ endogenous genomic sequences including a predicted promoter together with $0.8 \mathrm{~kb}$ of noncoding sequences in the first intron, and followed by a hemagglutinin (HA) tag (Fig. 1 A, black globule) inserted at the 3'end to distinguish exogenous from endogenous collagen XIII expression (Ylönen et al., 2005). Hence the

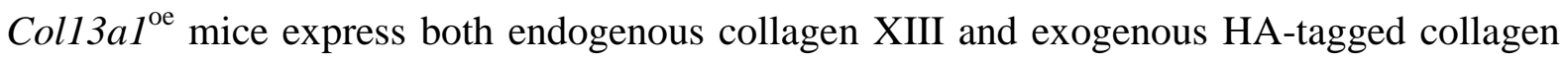
XIII, both of which can be shed (Fig. 1 A).

To compare the Coll3al ${ }^{\text {oe }}$ mice with the wild-type, we studied three muscle types: the respiratory muscle diaphragm, the mainly slow-twitch soleus muscle and the mainly fasttwitch extensor digitorum longus (EDL). In the wild-type mice Coll3al transcripts were most prevalent in the soleus, while the diaphragm and EDL contained $35 \%$ and $58 \%$ of the number in the soleus, respectively (Fig. 1 B). The Coll3al transcript levels in all the muscles studied were significantly increased in the $\operatorname{Coll}_{3} a 1^{\text {oe }}$ mice compared with the wild-type controls (Fig. $1 \mathrm{~B}$, diaphragm $\mathrm{p}=0.0001$, soleus $\mathrm{p}=0.0004$ and EDL $\mathrm{p}=0.0004$ ), the number being highest in the respiratory muscle diaphragm (29-fold relative to the wild-type) and lowest in the soleus muscle (3-fold). Furthermore, in the wild-type mice western blot analyses showed collagen XIII protein levels (Fig. 1 C-E), assessed by normalizing with the intensities of GAPDH in the corresponding muscles, to loosely follow the Coll3al transcript levels (Fig. 1 B). The total collagen XIII protein levels in the muscles of the Coll $3 a 1^{\text {oe }}$ mice 
were also in line with the transcript levels, in that they were clearly elevated in the diaphragm by 21 -fold $(2150.0 \pm 381.1 \%, \mathrm{~N}=2)$ relative to the wild-type diaphragm, which was defined as $100.0 \%$ for all other samples $(100.0 \pm 76.7 \%, \mathrm{~N}=3)$, and in the EDL muscles by 7 -fold $(86.9 \pm 71.7 \%, \mathrm{~N}=2)$ relative to the corresponding wild-type $(12.5 \pm 2.0 \%, \mathrm{~N}=3)$ but comparable $(125.1 \pm 44.2 \%, \mathrm{~N}=2)$ to the wild-type $(147.8 \pm 77.7 \%, \mathrm{~N}=3)$ in the soleus (Fig. 1 C-E). Muscles from collagen XIII knock-out $\left(\right.$ Coll3al $\left.^{-1-}\right)$ mice (Latvanlehto et al., 2010) served as negative controls for anti-collagen XIII antibodies (Kvist et al., 2001) in western blotting (Fig. $1 \mathrm{C}-\mathrm{E})$. Moreover, we discovered that in the wild-type mice in the diaphragm and soleus about $20 \%(16.8 \pm 12.5 \%$ and $16.9 \pm 2.9$, respectively) of the collagen XIII is in the form of a transmembrane protein (Fig. 1 C-E, arrowheads) and about $80 \%(83.2 \pm 12.5 \%$ and $83.1 \pm 2.9 \%$, respectively) is shed (Fig. $1 \mathrm{C}-\mathrm{E}$, arrows), while both transmembrane and shed forms represent about 50\% (53.8 $\pm 8.4 \%$ and $46.2 \pm 8.4 \%$, respectively) in the EDL. These ratios agree with previous analyses of wild-type muscles (Härönen et al., 2017). The shedding of exogenous collagen occurred with efficacy similar to the wild-type in the soleus (transmembrane $20.8 \pm 4.0 \%$ and shed 79.2. $\pm 4.0 \%$ ) and EDL muscles (transmembrane 51.6 $\pm 19.3 \%$ and shed $48.4 \pm 19.3 \%)$ of the Coll $3 a l^{\text {oe }}$ mice, while shedding in the diaphragm was decreased from $80 \%$, that of the wild-type, to $54 \%$ (transmembrane $46.0 \pm 2.5 \%$ and shed $54.0 \pm 2.5 \%$ ), indicating impaired shedding in conjunction with the highest overexpression (Fig. 1 B-C). Based on these observations, it is clear that, in addition to the bone (Ylönen et al., 2005), collagen XIII is also overexpressed in the muscle of Coll3al ${ }^{\text {oe }}$ mice. Interestingly, there is some variation in the levels of overexpression between different muscles in these mice, the diaphragm containing the highest levels and the soleus roughly normal levels of collagen XIII as assessed by western blotting. Furthermore, different muscles contain variable proportions of shed and transmembrane collagen XIII in the wildtype and the expression of exogenous collagen XIII does not have any effect on such 
proportions in the soleus and EDL muscles, although it does increase the proportion of transmembrane collagen XIII in the diaphragm of $\mathrm{Coll}_{3} \mathrm{I}^{\mathrm{oe}}$ mice.

\section{NMJ maturation is delayed and incomplete in $\mathrm{Coll3al}^{\text {oe }}$ mice}

To determine possible phenotypes in the muscle and at the NMJ, we first studied the effects of collagen XIII overexpression on NMJ maturation in Coll3al ${ }^{\text {oe }}$ mice. This involved evaluating the development of the AChR cluster pattern from birth to 25 weeks of age in the muscle with highest collagen XIII overexpression, the diaphragm, of wild-type and Coll3al ${ }^{\mathrm{oe}}$ mice. A lack of collagen XIII is known to delay NMJ maturation from two weeks of age onwards and produce immature, plaque-like AChR clusters in mice (Härönen et al., 2017; Latvanlehto et al., 2010) (Fig. 3 A-C), and similarly, overexpression of collagen XIII led to small, simple AChR clusters in the diaphragm of the Coll3al ${ }^{\text {oe }}$ mice (Fig. 2 A, arrowheads). This was obvious from 4 weeks onwards up to the last time-point studied, 25 weeks, and when analyzed at 12 weeks of age the AChR clusters were significantly decreased in size by $24 \%$ in the diaphragm of the Coll3al ${ }^{\mathrm{oe}}$ mice as compared with the controls (Fig. 2 D, $\mathrm{p}=0.0009$ ). Overexpression of collagen XIII also reduced the size of the AChR clusters in the soleus and EDL muscles at 12 weeks by $38 \%$ and $42 \%$, respectively (Fig. 2 B-C, arrowheads;

$2 \mathrm{D}$, soleus and EDL, $\mathrm{p}<0.0001)$. Interestingly, division of the AChR clusters into fragments was decreased only in the diaphragm of the Coll $3 a 1^{\text {oe }}$ mice, while it was comparable with the controls in the soleus and EDL muscles at 12 weeks (Fig. $2 \mathrm{E}$, diaphragm p=0.02, soleus $\mathrm{p}=0.67$ and EDL $\mathrm{p}=0.20$ ). This suggest that the AChR clusters in the diaphragm of Coll $3 \mathrm{al}^{\text {oe }}$ mice are indeed simpler than control clusters, but in the soleus and EDL the morphology of the NMJ is similar to that in the controls and only the size of the AChR clusters is reduced. The delayed and incomplete maturation of the AChR clusters in the Coll3al ${ }^{\mathrm{oe}}$ mice resembles the phenotype previously found in collagen XIII knock-out mice (Härönen et al., 2017; Latvanlehto et al., 2010).

This article is protected by copyright. All rights reserved. 


\section{Exogenous collagen XIII overexpression at synapse-rich muscle regions in $\mathrm{Coll3a1}^{\text {ee }}$ mice is not synaptic but extrasynaptic}

Due to the highly increased protein expression, especially in the diaphragm and EDL muscles of the Coll3al ${ }^{\mathrm{oe}}$ mice, we expected to find an increased accumulation of collagen XIII at the NMJs. Spots of collagen XIII were located in the AChR-positive areas of the NMJs in the wild-type muscles (Fig. 3 A-C), as previously shown (Härönen et al., 2017; Latvanlehto et

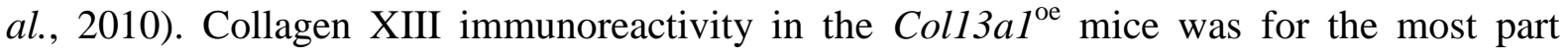
comparable to that in the wild-type controls in the postsynaptic areas of all the muscles studied (Fig. 3 A-C), but somewhat surprisingly, we could also detect NMJs without collagen XIII immunoreactivity in the Coll $3 a 1^{\text {oe }}$ mice, pronounced in the diaphragm (Fig. 3 A, asterisk). The $\mathrm{Coll}_{3} \mathrm{al}^{-/-}$mice were used as negative controls for the anti-collagen XIII antibody (Latvanlehto et al., 2010) (Fig. 3 A-C).

As suggested by the anti-collagen XIII antibody immunostainings, the immunoreactivity of the anti-HA-tag antibody did not reveal any exogenous expression of collagen XIII at the NMJs of the muscles studied in the Coll3al ${ }^{\text {oe }}$ mice (Fig. 3 D-F, asterisks). Instead of synaptic expression, we found extra collagen XIII immunoreactivity in two distinct locations in the vicinity of some NMJs in the diaphragm and EDL muscles in the Coll3al ${ }^{\mathrm{oe}}$ mice, although not exactly coinciding with the AChR-positive areas (Fig. 3 A, C). Firstly, the extra collagen XIII immunoreactivity formed structures extending from the postsynaptic apparatus, possibly suggesting a presynaptic association (Fig. $3 \mathrm{~A}, \mathrm{C}$, arrowheads). Secondly, most of the extrasynaptic collagen XIII immunoreactivity specifically in the diaphragm accumulated into cell-like processes without any clear association with the postsynaptic apparatus (Fig. 3 
A, arrows). Furthermore, HA-tag staining was found in the vicinity of the NMJs in the diaphragm and EDL muscles, at cell-like accumulations in the former and occasionally following axonal-like structures in both muscles (Fig. 3 D, F, arrows and arrowheads, respectively), thus resembling the extrasynaptic anti-collagen XIII antibodyimmunoreactivity (Fig. 3 A, C arrows and arrowheads, respectively). We conclude that unlike expected, the exogenous collagen XIII at synapse-rich muscle regions of the $\mathrm{Coll}_{3} \mathrm{al}^{\mathrm{oe}}$ mice does not accumulate at NMJs but in close association extrasynaptically, and presumably in connection with presynaptic axonal structures. Therefore, immunoreactivity of collagen XIII

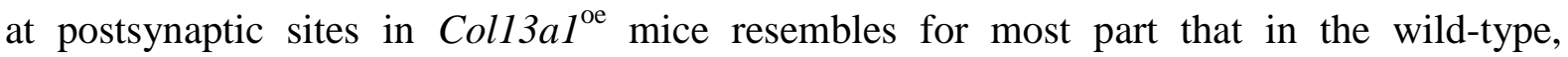
occasionally however mimicing the situation in knock-out mice. When evaluating the NMJrich regions, transgene collagen XIII is found expressed in the diaphragm and EDL, the very same muscles that have a clear increase in the transcript and protein levels of collagen XIII. However, in these muscles exogenous collagen XIII appears extrasynaptic and not synaptic. The transgene is thus incapable of driving synaptic overexpression of collagen XIII and instead it may hamper endogenous collagen XIII expression resulting in a decrease/lack of collagen XIII at the NMJ, especially in the diaphragm. Exogenous transgene expression thus leads to misexpression of collagen XIII at the NMJ in $C o l 13 a 1^{\mathrm{oe}}$ mice.

\section{Misexpression of collagen XIII causes axonal swelling and abnormal AChV accumulation in $\mathrm{Col13a1}^{\mathrm{oe}}$ mice}

Due to clear postsynaptic abnormalities, we set out next to study the effects of collagen XIII misexpression on the presynaptic structures. NMJs from the diaphragm, soleus and EDL muscles of wild-type and Coll3al ${ }^{\mathrm{oe}}$ mice were stained with an anti-neurofilament antibody (Fig. 4 A-C) to show the motor nerve cytoskeleton. All the studied NMJs were innervated 
and no polyneuronal innervation was detected. There was no difference in presynaptic complexity in the diaphragm muscle of the $\mathrm{Coll}_{3 a l^{\mathrm{ee}}}$ mice at 12 weeks of age, as the number of terminal divisions (Fig. 4 D, grey circles), branches (Fig. 4 D red arrowheads) and tips (Fig. 4 D, blue circles) in the presence of misexpression of collagen XIII was comparable to that in the controls (Fig. 4 E-G). Nevertheless, 64\% of the NMJs in the diaphragm of the

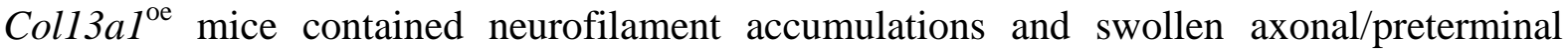
structures (Fig. $4 \mathrm{H}$; arrows in Fig. 4 A). These were significantly increased relative to the wild-type controls, where neurofilament-positive swelling of axons was seen only in $24 \%$ of the NMJs evaluated (Fig. $4 \mathrm{H}, \mathrm{p}=0.03$ ). There was no difference in ShC coverage, labeled with an anti-S100 antibody, between the $\mathrm{Coll}_{3} \mathrm{al}^{\mathrm{oe}}$ and wild-type mice at 12 weeks in any of the muscles studied (Fig. 4 I-K). Furthermore, staining for synaptotagmin-2 in the wild-type NMJs diffused evenly to cover the AChR-positive sites but revealed a patchier and somewhat more intense clustering of AChVs occasionally leaving some AChR-positive areas incompletely covered upon misexpression of collagen XIII in the diaphragm and soleus (Fig. 4 L-M, arrowheads and asterisks, respectively), although the differences between genotypes were not so obvious in the EDL (Fig. 4 N). We did not, however, detect any extra AChV clusters in the preterminal axons as reported for collagen XIII knock-out mice (Latvanlehto et al., 2010). We also investigated whether collagen XIII misexpression has any effect on the accumulation of voltage-dependent calcium channels (VDCCs), but could not detect any difference in the immunoreactivity of an anti-(P/Q-type, $\alpha$-1A subunit) -antibody between the wild-type and Coll3al ${ }^{\text {oe }}$ mice (Fig. 4 O-Q). Since AChE disperses from the AChR-positive clusters in collagen XIII deficient mice, as previously shown (Härönen et al., 2017), we studied the location of $\mathrm{AChE}$ in $\mathrm{Coll} 3 \mathrm{a} 1^{\mathrm{oe}}$ mice in more detail. However, no local differences in AChE distribution were detected in the NMJs relative to the controls by means of Fasciculin II in any of the muscles studied (Fig. 4 R-T). Altogether, these results indicate 


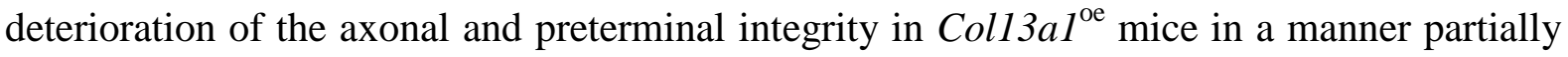
similar to that seen in collagen XIII knock-out mice (Härönen et al., 2017; Latvanlehto et al., 2010).

\section{Misexpression of collagen XIII leads to disruptions of synaptic adhesion and impairment in induced neurotransmission in $\mathrm{Col13a1}^{\mathrm{oe}}$ mice}

The effects of collagen XIII misexpression on presynaptic vesicle accumulation and the preterminal cytoskeleton led us to perform an ultrastructural analysis of the NMJs in the diaphragm. Transmission electron microscopy (TEM) revealed normal postsynaptic folding, but interestingly, interrupted adhesion of the nerve terminus and muscle in the Coll3al mice, and also ShC invaginations (Fig. 5 A-B, asterisks and arrowheads, respectively), similar to the effects shown previously for collagen XIII knock-out mice (Latvanlehto et al., 2010). In line with the autophagocytosis indicated by axonal neurofilament accumulations (Fig. 4 A-B, H), multilamellar inclusions, as a mark of neurodegeneration, were detected in the nerve termini of the Coll3al $1^{\text {oe }}$ mice (Fig. 5 A-B, arrows). While the motoneurons showed signs of degeneration, the numbers of AChVs and active zones (AZs; Fig. 5 A-B, red circles) were normal in the Coll3al $1^{\text {oe }}$ mice upon comparison with the controls (Fig. 5 C-D). The normal number of AZs was in line with normal VDCC immunoreactivity (Fig. 4 O-Q), but we were not able to detect any patchy clustering of AChVs in TEM similar to that seen with synaptotagmin-2 immunoreactivity (Fig. 4 L-M, arrowheads), although high variation suggests a tendency of uneven distribution (Fig. 5C).

To analyze whether the alterations in NMJ morphology in $C o l 13 a 1^{\text {oe }}$ mice have any effect on neurotransmission, electrophysiological measurements were performed. The resting membrane potential was normal in the diaphragm muscle of the adult $\mathrm{Coll}_{3} \mathrm{I}^{\mathrm{oe}}$ mice (data 
not shown). Also miniature endplate potential (MEPP) amplitude and frequency were unchanged in the Coll3al ${ }^{\text {oe }}$ mice relative to the controls (Fig. 6 A-C), indicating normal output and unaltered probability of spontaneous quantal release of ACh. The rise and decay times of the MEPPs were also unaltered, suggesting that the receptor kinetics were unchanged (wild-type $\mathrm{N}=9$, Coll $3 a 1^{\mathrm{oe}} \mathrm{N}=10$, both unpaired t-test, two-tailed; rise time $\mathrm{p}=0.42$ and decay time $\mathrm{p}=0.57$, no illustrations). However, in contrast to the collagen XIII knock-out mice the frequency of sucrose-induced MEPPs was significantly increased (Fig. 6 $\mathrm{D}-\mathrm{E}, \mathrm{p}=0.02)$, suggesting altered presynaptic function in the form of an increase in the size of the RRP of vesicles in the Coll3al ${ }^{\mathrm{oe}}$ mice similar to that previously reported for mice harboring only the transmembrane collagen XIII (Härönen et al., 2017).

Recordings of evoked endplate potentials (EPPs) showed slightly reduced amplitudes in the Coll3al $^{o e}$ mice (Fig. 6 F-I), as also in the absence of collagen XIII (Latvanlehto et al., 2010), since the amplitude of the last 100th repetitive peak of the evoked EPPs was significantly decreased relative to the controls (Fig. 6I, p<0.0001). This could be linked to the patchy, uneven $\mathrm{AChV}$ accumulation seen in the $\mathrm{Coll}_{3} \mathrm{al}^{\mathrm{oe}}$ mice at the light microscopy level (Fig. 4 L). We did not detect any difference between the Coll $3 a 1^{\text {oe }}$ mice and the controls in the amplitude of the first peak of the evoked EPPs and in the quantal content derived from that (Fig. $6 \mathrm{H}$, quantal content; both genotype $\mathrm{N}=8$, unpaired t-test, two-tailed: $\mathrm{p}=0.37$, no illustration). Furthermore, the EPP decay time was unchanged in the NMJs of the Coll3al diaphragms compared with the controls (both genotype $\mathrm{N}=8$, unpaired t-test, two-tailed: $\mathrm{p}=0.11$, no illustration). As above, the findings in the Coll $3 a 1^{\mathrm{oe}}$ mice at the ultrastructural and functional level resemble to some extent the phenotypes identified in the collagen XIII knock-out mice (Härönen et al., 2017; Latvanlehto et al., 2010). Furthermore, taken together, the increased sucrose-induced MEPP frequency and slightly decreased EPP amplitude in 
repetitive testing suggest slower replenishment, and thus faster depletion, of RRP in the Coll $3 a 1^{\mathrm{oe}}$ mice.

\section{Exogenous expression of collagen XIII in the muscles of $\mathrm{Coll3al}^{\text {oe }}$ mice is located primarily at the MTJs, in tenocytes and in fascial fibroblasts}

Despite highly increased transcript and protein levels in selected muscles of $\mathrm{Coll}_{3 a l^{\mathrm{oe}}}$ mice, the transgene collagen XIII did not accumulate at the NMJs. Instead, we identified higher levels at the myotendinous junction (MTJ), another known endogenous collagen XIII location in muscle (Hägg et al., 2001; Kvist et al., 2001; Latvanlehto et al., 2010). Indeed, we recorded increased aggregation of collagen XIII at the MTJs in the diaphragm (Fig. 7 A) and EDL (Fig. 7 C) of the Coll3al $1^{\text {oe }}$ mice, and also in the soleus (Fig. 7 B), even though protein analyses did not suggest any clear increase in the collagen XIII levels in this muscle (Fig. 1 D). In the wild-type muscles collagen XIII localized diffusively at the ends of the muscle fibers facing the adjacent tendon (Fig. 7 A-C, arrows). By contrast, collagen XIII immunoreactivity in the Coll3al ${ }^{\mathrm{oe}}$ mice extended over the head of muscle fibers and formed fibrillar-like structures, suggesting that collagen XIII was also located in the tendon of the diaphragm and soleus muscles (Fig. 7 A-B, arrowheads), although this was not that evident in the EDL (Fig. 7 C). Further immunostainings with the anti-HA-tag antibody revealed collagen XIII expression at the MTJs and tendons of the Coll3al ${ }^{\text {oe }}$ mice to be mainly of exogenous origin (Fig. 7 D-F).

As shown in the Fig. 3 A, we also observed multiple cell-like accumulations of collagen XIII immunoreactivity randomly on and within the diaphragm of the $\mathrm{Coll}_{3 a l^{\mathrm{oe}}}$ mice. When examining collagen XIII immunoreactivity in the diaphragm at low magnification, we could 
identify some collagen XIII-positive accumulations in the wild-type diaphragm, while these were greatly increased in number and intensity in the Coll3al ${ }^{\text {oe }}$ diaphragm (Fig. $7 \mathrm{G}$, arrows). In Z-projections such aggregations appeared to be localized on the infra- and supradiaphragmatic surfaces (Fig. 7 G, arrows). Again, further staining with the anti-HA-tag antibody showed most of the collagen XIII expression to be of exogenous origin (Fig. $7 \mathrm{H}$ ). Co-labeling with the anti-HA-tag antibody and DAPI indicated collagen XIII accumulations around the nucleus/in the cytoplasm and possibly at the plasma membrane of cells lying on the surface of the diaphragm and associations with blood vessels, but no co-localization with the endothelial marker PECAM-1 (Fig. 7 I, arrows). Instead, some co-localization was found with an anti- $\alpha$ smooth muscle actin ( $\alpha$-SMA; Fig. $7 \mathrm{~J}$, arrowheads) antibody which stains activated fibroblasts (Serini and Gabbiani, 1999) (Fig. 7 J, arrows). It can therefore be concluded that transgene collagen XIII is exogenously expressed mainly in the MTJs and tendons in the muscles of Coll3al ${ }^{\mathrm{oe}}$ mice, and additionally in fibroblast-like cells at the infraand supradiaphragmatic fasciae in the diaphragm muscle.

\section{Misexpression of collagen XIII causes aberrant muscle morphology in the diaphragm of}

\section{Coll3a1 $^{\mathrm{oe}}$ mice}

After confirming the pre- and postsynaptic changes upon the misexpression of collagen XIII and on the other hand over- and misexpression at the MTJ as well as in tendonal and fascial fibroblasts in the Coll3al ${ }^{\text {oe }}$ mice, we went on to evaluate the consequences of these for the muscle mass and morphology. First, the body mass analysis revealed a significant reduction in the weight of the Coll3al ${ }^{\text {oe }}$ females from 2 to 75 weeks of age (Fig. 8 A, 2 wk p=0.002; 4 wk $\mathrm{p}=0.04 ; 12$ wk $\mathrm{p}=0.03 ; 25$ wk $\mathrm{p}=0.03 ; 35$ wk $\mathrm{p}=0.02$ and 75 wk $\mathrm{p}=0.006$ ) and the males from 4 to 75 weeks of age (Fig. $8 \mathrm{~B}, 4$ wk p=0.02; 12 wk p=0.006; 25 wk p=0.04; 35 wk $\mathrm{p}=0.30$ and $75 \mathrm{wk} \mathrm{p}=0.01$ ) relative to the controls. 
Assessment of the muscle weight normalized by body mass at 4 and 12 weeks of age showed the weight of the diaphragm at both time points (Fig. $8 \mathrm{C}, 4 \mathrm{wk} p=0.03$ and $12 \mathrm{wk} \mathrm{p}=0.0007$ ) and the weight of the soleus at 12 weeks of age to have decreased significantly (Fig. 8 D, 4 wk $\mathrm{p}=0.71$ and 12 wk $\mathrm{p}<0.0001$ ), whereas the weight of the EDL was normal in the Coll $3 a 1^{\text {oe }}$ mice relative to the controls at both time points (Fig. 8 E). Histological studies of these muscles (Fig. $8 \mathrm{~F}-\mathrm{H})$ revealed changes only in the diaphragm of the Coll $3 a 1^{\mathrm{oe}}$ mice relative to the controls, where the number of small fibers was increased significantly at the expense of middle-sized fibers (Fig. 8 I, fibers sized $<500 \mu \mathrm{m}^{2} \mathrm{p}=0.04$ and fibers sized 500$\left.1000 \mu \mathrm{m}^{2} \mathrm{p}=0.04\right)$. The size distribution of the fibers was normal in the soleus and EDL

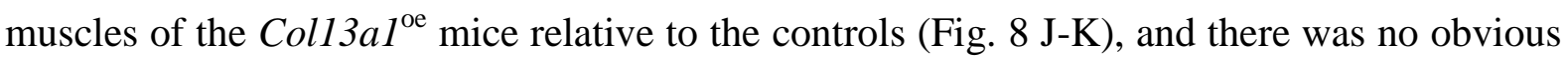
change in the number of central nuclei, a sign of muscle regeneration, in any muscle studied

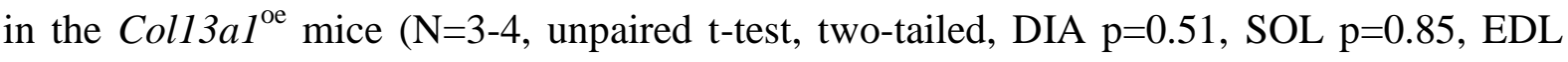
$\mathrm{p}=0.70$, no illustration), and a difference relative to the collagen XIII knock-out mice (Latvanlehto et al., 2010).

\section{Misexpression of collagen XIII results in dysmorphic patterns of motor nerves and}

\section{AChR clusters in Col13a1 $^{\mathrm{oe}}$ mice}

To evaluate the effect of the aberrant overexpression of collagen XIII in muscles of Coll3al $^{\text {oe }}$ mice on the neuromuscular system, the patterns of motor nerves and AChR clusters were studied on a tissue scale, whereupon the freshly imaged whole diaphragms revealed a dysmorphic motor nerve pattern in the Coll3al ${ }^{\text {oe }}$ mice as compared with the controls (Fig. 9 A). Misexpression of collagen XIII led to the secondary nerve branches being longer (Fig. 9 A, red lines) and less in number than in the controls (Fig. 9 B-C, length $\mathrm{p}=0.006$ and number $\mathrm{p}=0.0009$ ). In order to evaluate whether an extended nerve pattern of this kind will also influence the NMJ pattern in the diaphragm, we made use of AChE 
activity (Karnowsky and Roots, 1964), which revealed a significantly widened AChE pattern (Fig. 9 D-E, arrowheads, p=0.01). Moreover, the hemidiaphragm length (Fig. 9 A, green lines) was found to be about $14.5 \%$ greater in the $\mathrm{Coll}_{3 a l^{\mathrm{oe}}}$ mice than in the controls at the age of 12 weeks of age (Fig. $9 \mathrm{~F}, \mathrm{p}=0.03$ ). In line with the AChE pattern, a similarly widened AChR cluster pattern was also seen with $\alpha$-BTX stainings (Fig. 9 G, arrowheads), confirming that the AChE activity coincides with the NMJs. Next, we wanted to know whether this widening of the nerve and NMJ patterns evolves during development or postnatally, during maturation of the neuromuscular system. In fact, a similarly widened pattern was already to be found in the Col13al ${ }^{\mathrm{oe}}$ mice at E17.5 (Fig. $9 \mathrm{H}$, arrowheads), and they harbored distinctly collagen XIII-positive cell-like extrasynaptic processes (Fig. 9 I, arrows) similar to those in the mature diaphragm (Fig. 3 A, D and 7 G-J). Collagen XIII immunoreactivity with a faint, diffuse patterning coincided with $\alpha$-BTX staining synaptically in both genotypes (Fig. 9 I, arrowheads). The immunoreactivity of the anti-HA-tag antibody was in line with that of the extrasynaptic anti-collagen XIII antibody in the E17.5 diaphragm, but did not clearly accumulate at the NMJs of the Coll $3 a 1^{\text {oe }}$ mice, nor was it detected in the wild-type controls, as expected (Fig. $9 \mathrm{~J}$, arrows). Collagen XIII is thus already overexpressed in the diaphragm of the Coll3al ${ }^{\text {oe }}$ mice during development, presumably in fibroblast-like cells similar to those present in the adult muscle.

\section{DISCUSSION}

The observations presented here suggest that the correct expression and localization of collagen XIII is crucial for the normal formation and function of the neuromuscular system. Anomalous exogenous expression of collagen XIII was highly increased in the diaphragm, moderately increased in the EDL and roughly normal in the soleus. Interestingly, the expression of exogenous collagen XIII did not have any effect on the proportions of shed and 
transmembrane collagen XIII in the soleus and EDL muscles, whereas the highest collagen XIII overexpression in the Coll $3 a 1^{\text {oe }}$ mice, that found in the diaphragm, led to an increased proportion of the transmembrane form. Presumably the overexpression was so high that proteolytic processing could not cope with the increased synthesis required to maintain the ordinary level of shedding. Unexpectedly, the surplus collagen XIII expression was detected mainly in the extrasynaptic areas of the Coll3al ${ }^{\text {oe }}$ mouse muscles, especially in the diaphragm. While transgenic collagen XIII was either primarily or exclusively extrasynaptic, a proportion of the junctions were at the same time totally devoid of any collagen XIII immunosignal, either exogenous or endogenous. One explanation for the NMJs that were devoid of transgenic collagen XIII could arise from the fact that the genomic sequences used to regulate transcription of the collagen transgene construct, which in the case of bone and cartilage tissue results in transgene expression corresponding to the endogenous expression (Ylönen et al., 2005), drives muscular transgenic collagen XIII expression to extrasynaptic sites instead of the NMJs, thus pointing to separate regulatory elements for extrasynaptic and synaptic collagen XIII. In fact, prediction of consensus sequences for transcription factor binding sites (Latvanlehto et al., 2010) suggests that the genomic sequences around the first exon and included in the transgene construct contain several E-boxes, utilized for example by myogenin and MyoD, while N-boxes, recognized by Ets transcription factors and resulting in synaptic transcription, are not included (Funk et al., 1991; Mejat et al., 2003; Tang et al., 2006). Logan and colleagues found a human cDNA in the skeletal muscle to lack exons 3,5 , 6 and 30, while an earlier study suggested several splice variants all lacking exon 15 and a possibility of exons $6,14,31,35$ and/or 36 to be spliced out from Coll3al transcripts in the mouse skeletal muscle (Logan et al., 2015; Peltonen et al., 1997). The 689 nucleotide-long cDNA clone used to generate the Coll3al ${ }^{\text {oe }}$ mice lacked exons 15 and 31 (Peltonen et al., 1997; Snellman et al., 2000), therefore possibly representing one of the splice variants 
present in the mouse skeletal muscle. However, it is not known whether there exists distinct synaptic and extrasynaptic splice variants. Therefore, we speculate that HA-tagged $\alpha 1$ (XIII) chains produced in high numbers by the extrasynaptic nuclei nearby may trimerize with the endogenous synaptic collagen XIII alpha chains, thereby forming unstable mismatched trimers due to divergent sequence composition and length, and becoming targeted to degradation and resulting in a suicide effect (Veitia, 2007). As a result, some motor synapses in the diaphragm muscle lack collagen XIII, which would be a probable explanation for why many of the phenotypical changes at the NMJs in Coll3al ${ }^{\mathrm{oe}}$ mice resemble those previously detected in collagen XIII knock-out mice (Härönen et al., 2017; Latvanlehto et al., 2010).

Characterization of the Coll3al ${ }^{\mathrm{oe}}$ mice revealed delayed AChR maturation, as the AChR clusters remained morphologically small and simple in the diaphragm muscle in a manner similar to that observed in both murine and human collagen XIII deficiency (Latvanlehto et al., 2010; Logan et al., 2015). Immunofluorescence analyses of other NMJ components revealed normal accumulation of VDCCs and ShCs in all the muscles studied. Interestingly, the fine localization of $\mathrm{AChE}$ was also intact in the $\mathrm{Coll} 3 \mathrm{a} \mathrm{I}^{\mathrm{oe}}$ mice, unlike the situation in the Coll3al $^{-/-}$mice. Furthermore, while the presynaptic structures assessed in terms of neurofilament immunoreactivity revealed normal terminal complexity, we detected significantly increased numbers of neurofilament accumulations in the preterminal axons of the diaphragm upon overexpression of collagen XIII, suggesting neurodegenerative changes in the axons. Furthermore, AChV accumulation, detected by synaptotagmin-2 immunoreactivity, appeared patchy in the Coll3al ${ }^{\mathrm{oe}}$ mice, especially in the diaphragm and soleus muscles. Since this finding resembles previous observations made in collagen XIII knock-out mice (Härönen et al., 2017; Latvanlehto et al., 2010), this may reflect the detected collagen XIII deficiency in some of the NMJs in the Coll3al $1^{\text {oe }}$ mice. Ultrastructural and 
functional analyses of the NMJs were performed in the diaphragm muscle only, and in line with the axonal and preterminal findings, multilamellar accumulations in preterminal motoneurons were detected in ultrastructural analysis and interpreted as a sign of neurodegeneration. Moreover, interruptions in nerve-muscle adhesion were found, together with ShC invaginations into the junction area similar to those reported previously in cases of collagen XIII deficiency (Latvanlehto et al., 2010). Functional analysis revealed normal spontaneous activity of the neuromuscular synapses, but an increase in the RRP of AChVs, although the numbers of vesicles and AZs were ultrastructurally normal. Although the RRP of AChVs was increased, repetitive electrical nerve stimulation showed slightly decreasing amplitudes of EPPs, indicating slower replenishing rates for this pool of vesicles. This could result from the intense but patchy accumulation of $\mathrm{AChVs}$ seen at the light microscopy level, suggesting that the reserve pools of AChVs are not correctly organized in the Coll3al ${ }^{\mathrm{oe}}$ mice.

The diaphragm was the most affected by the overexpression of collagen XIII among the muscles studied here, clearly exhibiting an aberrant morphology with smaller muscle fibers and reduced muscle width accompanied by an extended hemidiaphragm length. It was the only muscle that histologically harbored clear signs of myasthenia and a decrease in mass at P28 and P84 as signs of muscle atrophy or immaturity. Defects in maturation were more likely to appear, as the number of centrally located nuclei in the diaphragm of the Coll $3 a 1^{\text {oe }}$ mice was not increased as an indication of muscle regeneration. Furthermore, the nerve and AChR patterns were found to be widened from a central band towards the lateral edges of the

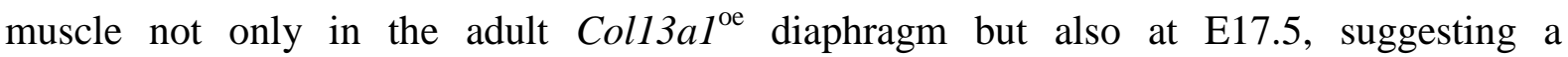
developmental origin for this phenotype. Collagen XIII immunoreactivity in the E17.5 diaphragm of the wild-type and Coll3al ${ }^{\mathrm{oe}}$ fetuses was diffusely localized in the AChR- 
positive areas, while the diaphragm of the $\operatorname{Col} 13 a l^{\text {oe }}$ fetuses harbored cell-like accumulations that were positive for collagen XIII in the same way as in the adults, and further stainings with the HA-tag antibody revealed such expression to be of exogenous origin. Even though the NMJs of the collagen XIII overexpression and absence models resembled each other to some extent in terms of morphology and function, the weight of the diaphragm was unaltered in the Coll3al $1^{-/-}$mice and the only visible difference was the smaller muscle fibers (Härönen et al., 2017). It could thus be suggested that the NMJ abnormality in the Coll3al ${ }^{\mathrm{oe}}$ mice is not solely responsible for the aberrant muscle histology and nerve patterning, as such findings may result from extrasynaptic changes occurring in the presence of collagen XIII overexpression.

Exogenous collagen XIII expression was found at four distinct locations in the Coll3al ${ }^{\text {oe }}$ mice: (1) alongside the endogenous muscle fiber expression at the MTJs of all the muscles studied and (2) distinct from the endogenous expression most likely in the tenocytes on the tendon side, and (3) in the fibroblast cell-like structures on and within the muscle and (4) in the near vicinity of the NMJs, possibly in association with presynaptic axonal structures. Collagen XIII immunoreactivity was found accumulated especially at the infra- and supradiaphragmatic fasciae in the diaphragm of the Coll $3 a 1^{\text {oe }}$ mice, resembling a fibroblastlike cell morphology, and was localized unipolarly around the nucleus in these cells, at the cell periphery and possibly at the plasma membrane. Collagen XIII immunoreactivity has previously been found in vitro at focal adhesions in cultured human cutaneous fibroblasts, colocalizing with vinculin and talin at the end of actin filaments (Hägg et al., 2001). Furthermore, we found some immunoreactivity of $\alpha$-SMA within these cells, suggesting a myofibroblast-like cell phenotype. In view of the localization of these cells at the infra- and supradiaphragmatic fasciae, one could postulate that they might be fascial fibroblasts 
overexpressing collagen XIII. The existence of endogenous collagen XIII expression, albeit at a very low level, in some of these cells in the wild-type diaphragm confirmed that they are adjusted for collagen XIII expression. For example, the activity of the collagen XIII promoter used to generate the Coll3al ${ }^{\mathrm{oe}}$ mice was originally tested and evaluated in fibroblast cells (Ylönen et al., 2005). In addition to these cell-like accumulations, we consider it possible that the diffuse occurrence of exogenous collagen XIII in the vicinity of the NMJs may represent a novel and poorly characterized fourth cell type at the NMJs, fibroblast-like kranocytes, capping the NMJ and co-localizing presynaptically with ShCs (Court et al., 2008). Kranocytes have been shown to react upon denervation and muscle atrophy, but their precise function at the NMJ remains obscure (Court et al., 2008).

It is known that connective tissue and muscles are tightly coordinated both temporally and spatially in terms of their development, and that fibroblasts generally promote muscle maturation and formation in myoblast cultures (Murphy et al., 2011). Collagen XIII overexpression in the diaphragmic fibroblast-like cells found in $\mathrm{Coll}_{3} \mathrm{al} \mathrm{oe}^{\mathrm{oe}}$ mice is so marked that it may interfere with the normal behavior and function of these cells in myogenesis. Although the diaphragm muscle in the $\operatorname{Coll}_{3} a 1^{\text {oe }}$ mice is large in size it is lighter than the wild-type, on account of a significant decrease of $35 \%$ in its width $(230 \pm 23.65 \mu \mathrm{m}$ at P84 in Col13al ${ }^{\text {oe }}$ mice, $355.5 \pm 21.79 \mu \mathrm{m}$ in the wild-type, Mann Whitney test: $\mathrm{p}=0.03, \mathrm{~N}=4$ in both genotypes, no illustration). Interestingly, collagen XIII overexpression in osteoblasts of corresponding mice also changes the fate of these cells by promoting their proliferation, finally leading to massive bone over-growth (Ylönen et al., 2005). In the absence of a tool for detecting these cells in the muscles of both wild-type and $C o l 13 a 1^{\text {oe }}$ mice, we cannot confirm whether overexpression of collagen XIII might lead to proliferation of these fibroblast-like cells in the same manner as osteoblasts. However, MyoD, a muscle-specific transcription 
factor, the deficiency of which leads to an aberrantly widened AChR cluster and nerve pattern in mice, is also needed for myoblast differentiation, suggesting that altered muscle development may lead to altered NMJ development (Z. Z. Wang et al., 2003). This could also provide an explanation for the defects detected in the aberrant presence of collagen XIII overexpression. On the other hand, collagen XXV, a highly homologous molecule to collagen XIII, has proved indispensable for developmental intramuscular innervation (Tanaka et al., 2014). We did not see as drastic a phenotype in the absence of collagen XIII (Härönen et al., 2017; Latvanlehto et al., 2010), although there was an obvious aberrant nerve pattern in the Col13al ${ }^{\mathrm{oe}}$ mice. Could collagen XIII act as an attractant for the nerves and lead to a widened nerve pattern when expressed extrasynaptically? Interestingly, and in support of this idea, the recombinant collagen XIII ectodomain was found to enhance neurite outgrowth in vitro in primary neuronal cell cultures extracted from the E18.5 fetal rat hippocampus (Sund et al., 2001). As mentioned, the length of the diaphragm muscle was also increased, suggesting that the muscle fibers are either extended in length or alternatively two or more sequential fibers occupy the same length of muscle, whereupon these fibers may be smaller in diameter. The latter option could also easily explain the lengthening detected in the axonal branches and the broadening of the established motor synapse pattern in the Coll3al ${ }^{\mathrm{oe}}$ mice. Since we did not study the AChR cluster patterning on the earlier embryonal days, representing pre-patterning, hence we cannot rule out the possibility that the widened nerve and AChR pattern could already have resulted from a pre-patterning defect, as in $\mathrm{AChR} \gamma^{(\varepsilon / \varepsilon)}$ mice or in the absence of the $\beta 1$ subunit of the dihydropyridine receptor (DHPR) (Chen et al., 2011; Koenen et al., 2005). On the other hand, the widened distribution of AChR clusters and nerves could not result from a lack of synapse formation, as in the deterioration of the agrin-MuSK signaling axis (DeChiara et al., 1996; Gautam et al., 1996; Okada et al., 2006), because synapses do

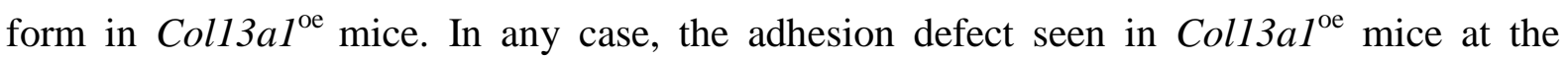


ultrastructural level is not sufficient to explain the phenotype. If that were the case, also collagen XIII deficient mice harboring a similar disassociation in the muscles and nerves would present a similarly widened AChR and nerve pattern, but they do not (Latvanlehto et al., 2010). A more appealing explanation could arise from an aberrant downregulation of synaptic gene transcription outside the prospective endplate band upon the overexpression of collagen XIII at extrasynaptic sites, as seen in the absence of the agrin-MuSK signaling axis, for example, and further suggested in the case of MyoD null mice (Gautam et al., 1996; Okada et al., 2006; Z. Z. Wang et al., 2003).

In the presence of collagen XIII overexpression we detected by immunohistochemical means an extension of the accumulation of collagen XIII in the MTJs from the head of muscle fibers into the tendon area, and also a tendency for fibroblast-like cells, possibly representing tenocytes, to overexpress collagen XIII at the tendons. Previous studies with mice expressing $\mathrm{N}$-terminally altered collagen XIII showed variations in muscle fiber size, a disorganized and fuzzy sarcolemma and a particularly prominent adjacent BM at the MTJs in these mice (Kvist et al., 2001). In a way, the above results obtained in mice expressing $\mathrm{N}$-terminally altered collagen XIII suggest that this collagen may participate in stabilizing the MTJs. The highly increased amount of collagen XIII in the tendons and at the MTJs seen in Coll $3 a 1^{\text {oe }}$ mice may affect the mechanical and force-bearing properties of such structures and indirectly lead to endangered muscle integrity.

We show here that unlike in bone, the ectopic expression of collagen XIII in the skeletal muscle of Coll3al ${ }^{\mathrm{oe}}$ mice does not well recapitulate the endogenous expression pattern. Furthermore, this may also be the case in some other tissues yet unstudied, and account for 
the debilitating effects seen for example as the retarded growth observed in our study. All in all, the present findings confirm the role of collagen XIII in the neuromuscular system and highlight the importance of its correct expression and localization in the musculoskeletal tissues, a fact that should be taken into account in possible future attempts to develop treatment for patients suffering from CMS19. They also justify further studies on muscle and NMJ development in collagen XIII-deficient mice to explore the congenital nature of CMS19.

\section{ACKNOWLEDGEMENTS}

This work was supported by the Sigrid Jusélius Foundation and the University of Oulu Graduate School through the Biocenter Oulu doctoral program. We thank Sirkka Vilmi for her technical assistance. We also thank the Biocenter Oulu Light and Electron Microscopy Core Facilities, supported by the University of Oulu and Biocenter Finland, and the University of Oulu Animal Facility for expert help and access to equipment.

\section{COMPETING INTERESTS}

The authors have declared that no conflicts of interest exist.

\section{AUTHOR CONTRIBUTIONS}

H.H., R.G., T.P. and A.H. designed the experiments. A.H. maintained the mouse lines. H.H. made sampling assisted by Z.Z., A.V.K. and A.H., performed the (immuno)histology and imaging, assisted by Z.Z., S.S., and A.H., and implemented the morphometric analyses. H.H. performed the protein- and transcript-level quantifications, assisted by A.H. N.N. and A.S. 
performed the electrophysiological experiments, supervised by R.G., while R.S. and I.M. performed the electron microscopy, assisted by H.H. and Z.Z. The statistical analyses were performed by H.H. and A.H. H.H., R.G., T.P. and A.H. interpreted the results and wrote the manuscript.

\section{DATA ACCESSIBILITY}

Data sets are available on request from the corresponding author.

\section{ABBREVIATIONS}

$\mathrm{AChE}=$ acetylcholine esterase, $\mathrm{AChR}=$ acetylcholine receptor, $\mathrm{AChV}=$ acetylcholine vesicle, $\mathrm{AZ}=$ active zone, $\mathrm{BM}=$ basement membrane, $\mathrm{COL}=$ collagenous domain, $\mathrm{Col} \mathrm{Q}=\mathrm{Collagen} \mathrm{Q}$, CMS19=congenital myasthenic syndrome type 19, E=embryonic day, ECM=extracellular matrix, EDL=extensor digitorum longus muscle, EPP=evoked endplate potential, $\mathrm{HA}=$ hemagglutinin, $\mathrm{MEPP}=$ miniature endplate potential, $\mathrm{MTJ}=$ myotendinous junction, $\mathrm{NC}=$ non-collagenous domain, $\mathrm{NMJ}=$ neuromuscular junction, $\mathrm{P}=$ postnatal day, $\mathrm{RRP}=$ readily releasable pool, $\mathrm{ShC}=\mathrm{Schwann}$ cell, $\mathrm{TEM}=$ transmission electron microscopy, VDCC $=$ voltage-dependent calcium channel

This article is protected by copyright. All rights reserved. 


\section{REFERENCES}

Arikawa-Hirasawa, E., Rossi, S.G., Rotundo, R.L. \& Yamada, Y. (2002) Absence of acetylcholinesterase at the neuromuscular junctions of perlecan-null mice. Nat. Neurosci., $\mathbf{5}$, 119-123.

Chen, F., Liu, Y., Sugiura, Y., Allen, P.D., Gregg, R.G. \& Lin, W. (2011) Neuromuscular synaptic patterning requires the function of skeletal muscle dihydropyridine receptors. Nat. Neurosci., 14, 570-577.

Court, F. A., Gillingwater, T.H., Melrose, S., Sherman, D.L., Greenshields, K.N., Morton, A.J., Harris, J.B., Willison, H.J. \& Ribchester, R.R. (2008) Identity, developmental restriction and reactivity of extralaminar cells capping mammalian neuromuscular junctions. J. Cell. Sci., 121, 3901-3911.

DeChiara, T. M., Bowen, D.C., Valenzuela, D.M., Simmons, M.V., Poueymirou, W.T., Thomas, S., Kinetz, E., Compton, D.L., Rojas, E., Park, J.S., Smith, C., DiStefano, P.S., Glass, D.J., Burden, S.J. \& Yancopoulos, G.D. (1996) The receptor tyrosine kinase MuSK is required for neuromuscular junction formation in vivo. Cell, 85, 501-512.

Fox, M. A., Ho, M.S., Smyth, N. \& Sanes, J.R. (2008) A synaptic nidogen: Developmental regulation and role of nidogen-2 at the neuromuscular junction. Neural Develop, 3, 24.

Funk, W. D., Ouellette, M. \& Wright, W.E. (1991) Molecular biology of myogenic regulatory factors. Mol. Biol. Med., 8, 185-195.

Gautam, M., Noakes, P.G., Moscoso, L., Rupp, F., Scheller, R.H., Merlie, J.P. \& Sanes, J.R. (1996) Defective neuromuscular synaptogenesis in agrin-deficient mutant mice. Cell, 85, $525-535$.

Hägg, P., Väisänen, T., Tuomisto, A., Rehn, M., Tu, H., Huhtala, P., Eskelinen, S. \& Pihlajaniemi, T. (2001) Type XIII collagen: A novel cell adhesion component present in a range of cell-matrix adhesions and in the intercalated discs between cardiac muscle cells. Matrix Biol., 19, 727-742.

Hägg, P., Rehn, M., Huhtala, P., Väisänen, T., Tamminen, M. \& Pihlajaniemi, T. (1998) Type XIII collagen is identified as a plasma membrane protein. J. Biol. Chem., 273, 1559015597.

Härönen, H., Zainul, Z., Tu, H., Naumenko, N., Sormunen, R., Miinalainen, I., Shakirzyanova, A., Oikarainen, T., Abdullin, A., Martin, P., Santoleri, S., Koistinaho, J., Silmanl, I., Giniatullin, R., Fox, M.A., Heikkinen, A. \& Pihlajaniemi, T. (2017) Collagen XIII secures pre- and postsynaptic integrity of the neuromuscular synapse. Hum. Mol. Genet., 26, 2076-2090.

Hong, S. J. \& Chang, C.C. (1993) Transmitter-mediated local contracture of the endplate region of the focally innervated mouse diaphragm treated with anticholinesterase. Br. J. Pharmacol., 109, 1178-1185.

This article is protected by copyright. All rights reserved. 
Karnowsky, M. J. \& Roots, L. (1964) A "direct-coloring" thiocholine method for cholinesterases. J. Histochem. Cytochem., 12, 219-221.

Kashani, A. H., Chen, B.M. \& Grinnell, A.D. (2001) Hypertonic enhancement of transmitter release from frog motor nerve terminals: $\mathrm{Ca} 2+$ independence and role of integrins. J.

Physiol., 530, 243-252.

Koenen, M., Peter, C., Villarroel, A., Witzemann, V. \& Sakmann, B. (2005) Acetylcholine receptor channel subtype directs the innervation pattern of skeletal muscle. EMBO Rep., 6 , 570-576.

Kvist, A. P., Latvanlehto, A., Sund, M., Eklund, L., Väisänen, T., Hägg, P., Sormunen, R., Komulainen, J., Fässler, R. \& Pihlajaniemi, T. (2001) Lack of cytosolic and transmembrane domains of type XIII collagen results in progressive myopathy. Am. J. Pathol., 159, 15811592.

Latvanlehto, A., Fox, M.A., Sormunen, R., Tu, H., Oikarainen, T., Koski, A., Naumenko, N., Shakirzyanova, A., Kallio, M., Ilves, M., Giniatullin, R., Sanes, J.R. \& Pihlajaniemi, T. (2010) Muscle-derived collagen XIII regulates maturation of the skeletal neuromuscular junction. J. Neurosci., 30, 12230-12241.

Logan, C. V., Cossins, J., Rodriguez Cruz, P.M., Parry, D.A., Maxwell, S., MartinezMartinez, P., Riepsaame, J., Abdelhamed, Z.A., Lake, A.V., Moran, M., Robb, S., Chow, G., Sewry, C., Hopkins, P.M., Sheridan, E., Jayawant, S., Palace, J., Johnson, C.A. \& Beeson, D. (2015) Congenital myasthenic syndrome type 19 is caused by mutations in COL13A1, encoding the atypical non-fibrillar collagen type XIII alphal chain. Am. J. Hum. Genet., 97, 878-885.

Martin, P. T., Kaufman, S.J., Kramer, R.H. \& Sanes, J.R. (1996) Synaptic integrins in developing, adult, and mutant muscle: Selective association of alpha1, alpha7A, and alpha7B integrins with the neuromuscular junction. Dev. Biol., 174, 125-139.

Mejat, A., Ravel-Chapuis, A., Vandromme, M. \& Schaeffer, L. (2003) Synapse-specific gene expression at the neuromuscular junction. Ann. N. Y. Acad. Sci., 998, 53-65.

Murphy, M. M., Lawson, J.A., Mathew, S.J., Hutcheson, D.A. \& Kardon, G. (2011) Satellite cells, connective tissue fibroblasts and their interactions are crucial for muscle regeneration. Development, 138, 3625-3637.

Okada, K., Inoue, A., Okada, M., Murata, Y., Kakuta, S., Jigami, T., Kubo, S., Shiraishi, H., Eguchi, K., Motomura, M., Akiyama, T., Iwakura, Y., Higuchi, O. \& Yamanashi, Y. (2006) The muscle protein dok-7 is essential for neuromuscular synaptogenesis. Science, 312, 18021805 .

Peltonen, S., Rehn, M. \& Pihlajaniemi, T. (1997) Alternative splicing of mouse alpha1(XIII) collagen RNAs results in at least 17 different transcripts, predicting alpha1(XIII) collagen chains with length varying between 651 and 710 amino acid residues. DNA Cell Biol., 16, 227-234.

Peng, H. B., Xie, H., Rossi, S.G. \& Rotundo, R.L. (1999) Acetylcholinesterase clustering at

This article is protected by copyright. All rights reserved. 
the neuromuscular junction involves perlecan and dystroglycan. J. Cell Biol., 145, 911-921.

Sara, Y., Mozhayeva, M.G., Liu, X. \& Kavalali, E.T. (2002) Fast vesicle recycling supports neurotransmission during sustained stimulation at hippocampal synapses. J. Neurosci., 22, 1608-1617.

Serini, G. \& Gabbiani, G. (1999) Mechanisms of myofibroblast activity and phenotypic modulation. Exp. Cell Res., 250, 273-283.

Snellman, A., Tu, H., Väisänen, T., Kvist, A.P., Huhtala, P. \& Pihlajaniemi, T. (2000) A short sequence in the $\mathrm{N}$-terminal region is required for the trimerization of type XIII collagen and is conserved in other collagenous transmembrane proteins. EMBO J., 19, 5051-5059.

Souza, P. V., Batistella, G.N., Lino, V.C., Pinto, W.B., Annes, M. \& Oliveira, A.S. (2016) Clinical and genetic basis of congenital myasthenic syndromes. Arq. Neuropsiquiatr., 74, 750-760.

Spandidos, A., Wang, X., Wang, H. \& Seed, B. (2010) PrimerBank: A resource of human and mouse PCR primer pairs for gene expression detection and quantification. Nucleic Acids Res., 38, D792-9.

Spandidos, A., Wang, X., Wang, H., Dragnev, S., Thurber, T. \& Seed, B. (2008) A comprehensive collection of experimentally validated primers for polymerase chain reaction quantitation of murine transcript abundance. BMC Genomics, 9, 633-2164-9-633.

Sund, M., Väisänen, T., Kaukinen, S., Ilves, M., Tu, H., Autio-Harmainen, H., Rauvala, H. \& Pihlajaniemi, T. (2001) Distinct expression of type XIII collagen in neuronal structures and other tissues during mouse development. Matrix Biol., 20, 215-231.

Tanaka, T., Wakabayashi, T., Oizumi, H., Nishio, S., Sato, T., Harada, A., Fujii, D., Matsuo, Y., Hashimoto, T. \& Iwatsubo, T. (2014) CLAC-P/collagen type XXV is required for the intramuscular innervation of motoneurons during neuromuscular development. J. Neurosci., 34, 1370-1379.

Tang, H., Veldman, M.B. \& Goldman, D. (2006) Characterization of a muscle-specific enhancer in human MuSK promoter reveals the essential role of myogenin in controlling activity-dependent gene regulation. J. Biol. Chem., 281, 3943-3953.

Tu, H., Sasaki, T., Snellman, A., Gohring, W., Pirilä, P., Timpl, R. \& Pihlajaniemi, T. (2002) The type XIII collagen ectodomain is a $150-\mathrm{nm}$ rod and capable of binding to fibronectin, nidogen-2, perlecan, and heparin. J. Biol. Chem., 277, 23092-23099.

Väisänen, M. R., Väisänen, T. \& Pihlajaniemi, T. (2004) The shed ectodomain of type XIII collagen affects cell behaviour in a matrix-dependent manner. Biochem. J., 380, 685-693.

Veitia, R. A. (2007) Exploring the molecular etiology of dominant-negative mutations. Plant Cell, 19, 3843-3851.

Virmani, T., Ertunc, M., Sara, Y., Mozhayeva, M. \& Kavalali, E.T. (2005) Phorbol esters target the activity-dependent recycling pool and spare spontaneous vesicle recycling. J.

This article is protected by copyright. All rights reserved. 
Neurosci., 25, 10922-10929.

Wang, X. \& Seed, B. (2003) A PCR primer bank for quantitative gene expression analysis. Nucleic Acids Res., 31, e154.

Wang, Z. Z., Washabaugh, C.H., Yao, Y., Wang, J.M., Zhang, L., Ontell, M.P., Watkins, S.C., Rudnicki, M.A. \& Ontell, M. (2003) Aberrant development of motor axons and neuromuscular synapses in MyoD-null mice. J. Neurosci., 23, 5161-5169.

Ylönen, R., Kyrönlahti, T., Sund, M., Ilves, M., Lehenkari, P., Tuukkanen, J. \& Pihlajaniemi, T. (2005) Type XIII collagen strongly affects bone formation in transgenic mice. J. Bone Miner. Res., 20, 1381-1393.

Zainul, Z., Heikkinen, A., Koivisto, H., Rautalahti, I., Kallio, M., Lin, S., Härönen, H., Norman, O., Rüegg, M.A., Tanila, H. \& Pihlajaniemi, T. (2018) Collagen XIII is required for neuromuscular synapse regeneration and functional recovery after peripheral nerve injury. $\mathrm{J}$. Neurosci., 38, 4243-4258.

\section{FIGURE CAPTIONS}

\section{Figure 1. Muscles of $\mathrm{Coll3a1}^{\mathrm{oe}}$ mice overexpress collagen XIII}

(A) Schematic presentation of the endogenous and exogenous transmembrane and shed collagen XIII proteins in wild-type $\left(\mathrm{Coll}_{3} \mathrm{al}^{+/+}\right)$and transgenic collagen XIII overexpression $\left(\right.$ Coll3al $\left.^{\mathrm{oe}}\right)$ mice. The helical structures indicate collagenous domains (COL1-COL3), globular structures non-collagenous domains (NC1-NC4) and black globules the HA-tag in exogenous collagen XIII. (B) Coll3al transcripts in the diaphragm (DIA), soleus (SOL) and

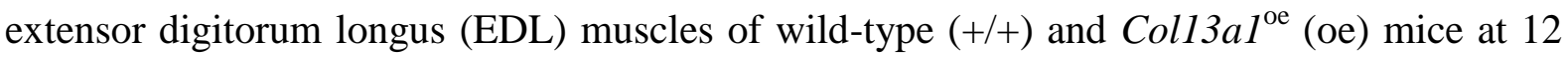
weeks of age as shown by RT-qPCR. The mean value for the transcript levels in the wildtype diaphragm muscle is defined as $100 \%$ in artificial units. N(DIA;SOL;EDL): wild-type

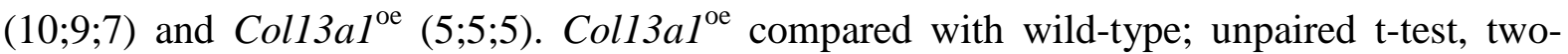
tailed: DIA $\mathrm{p}=0.0001, \mathrm{SOL} \mathrm{p}=0.0004$ and EDL $\mathrm{p}=0.0004$. Wild-type (muscle) to wild-type (DIA); unpaired t-test, two-tailed: SOL $\mathrm{p}=0.0005$ and EDL $\mathrm{p}=0.01$ (no illustration). $* * * \mathrm{p}<0.001$. (C-E) Collagen XIII (ColXIII) western blot and GAPDH as a loading control in 
the diaphragm (C), soleus (D) and EDL (E) at 12 weeks of age. Arrows indicate the shed $(\approx 90-95 \mathrm{kDa})$ and arrowheads the transmembrane $(\approx 95-100 \mathrm{kDa})$ collagen XIII.

\section{Figure 2. NMJ maturation is delayed and $\mathrm{AChR}$ cluster size is reduced in $\mathrm{Coll3a1}^{\mathrm{oe}}$} mice

(A-C) Immunofluorescent confocal images of AChR clusters labeled with $\alpha$-bungarotoxin ( $\alpha$ BTX) in the wild-type (+/+) and Coll3al ${ }^{\mathrm{oe}}$ (oe) diaphragm (DIA) at 0, 2, 4, 8, 12 and 25 weeks (wk) of age (A), soleus (SOL, B) and EDL (C) at 12 weeks of age. Arrowheads indicate small, simple clusters. Bars are $10 \mu \mathrm{m}$. (D-E) Quantification of the areas of AChR clusters (D) and numbers of AChR fragments per NMJ (E) in the diaphragm, soleus and EDL

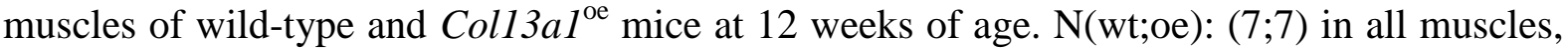
n(total number of calculated NMJs in DIA; SOL; EDL): wild-type $(63 ; 59 ; 57)$ and Coll3al $1^{\text {oe }}$ (63;59;57). Unpaired t-test, two-tailed: DIA $\mathrm{p}=0.0009$, Mann-Whitney, two-tailed: SOL and EDL $p<0.0001$ (D). Mann-Whitney, two-tailed, exact p-values: DIA p=0.02, SOL p=0.67 and EDL $p=0.20(E)$. The data in D-E are presented NMJ-wise. ${ }^{*} p<0.05, * * * p<0.001$, ns $=$ not significant.

\section{Figure 3. Exogenous collagen XIII does not accumulate at the NMJs of $\mathrm{Coll3a1}^{\mathrm{oe}}$ mice $^{-1}$} (A-C) Co-staining for collagen XIII (ColXIII; red) and ( $\alpha$-BTX; green) to show AChRs in the diaphragm (DIA, A), soleus (SOL, B) and EDL (C) of wild-type (+/+) and Coll $3 a 1^{\text {oe }}(\mathrm{oe})$ mice, and of Coll3al ${ }^{-/-}(-/-)$mice (C) at 12 weeks of age. (D-F) Co-staining with the antiHA-tag antibody (HA-tag; red) to show exogenous collagen XIII expression and $\alpha$-BTX (green) in the DIA (D), SOL (E) and EDL muscle (F). Arrows indicate extrasynaptic immunoreactivity accumulating in cell-like processes, arrowheads indicate structures extending from the postsynaptic apparatus, and asterisks indicate NMJs without immunoreactivity. Bars are $10 \mu \mathrm{m}$.

This article is protected by copyright. All rights reserved. 
Figure 4. Misexpression of collagen XIII causes axonal swelling and abnormal AChV accumulation in $\mathrm{Coll3a1}^{\mathrm{oe}}$ mice

(A-C) Co-staining of the diaphragm (DIA, A), soleus (SOL, B) and EDL (C) in wild-type $(+/+)$ and Coll3al $^{\text {oe }}$ (oe) mice at 12 weeks of age with an anti-neurofilament antibody (NF; red) to show the nerve cytoskeleton and $\alpha$-BTX (green) to show AChRs. Arrows indicate swollen nerve branches. Bars are $10 \mu \mathrm{m}$. (D) Schematic presentation of the nerve and axonal divisions (grey circle), branches (red arrowhead) and tips (blue circle). (E-H) Quantification of the neurofilament pattern in the diaphragm showing the numbers of terminal divisions $(\mathrm{E})$, branches (F) and tips $(\mathrm{G})$ per NMJ and percentages of NMJs per mouse with swollen axonal branches $(\mathrm{H}) . \mathrm{N}(\mathrm{wt} ; \mathrm{oe})$ : $(4 ; 4)$ and $\mathrm{n}($ total number of NMJs in wt;oe): $(27 ; 27)$. The data are presented NMJ-wise in E-G and mouse-wise in H. Mann-Whitney, two-tailed, exact p-values: divisions $\mathrm{p}=0.12(\mathrm{E})$, branches $\mathrm{p}=0.19(\mathrm{~F})$ and $\mathrm{NF}$ accumulations $\mathrm{p}=0.03(\mathrm{H})$, unpaired t-test, two-tailed: tips $\mathrm{p}=0.48(\mathrm{G}) .{ }^{*} \mathrm{p}<0.05$, ns=not significant. (I-R) Co-labeling of the diaphragm (I, L, O, R), soleus $(\mathrm{J}, \mathrm{M}, \mathrm{P}, \mathrm{S})$ and $\operatorname{EDL}(\mathrm{K}, \mathrm{N}, \mathrm{Q}, \mathrm{T})$ in wild-type and Coll3al ${ }^{\mathrm{oe}}$ mice at 12 weeks of age with an anti-S100 antibody (red) to show ShCs and $\alpha$-BTX (green) (I-K), with an anti-synaptotagmin 2 antibody (Syt-2; green) to show AChVs and $\alpha$-BTX (blue) (L-N),

with an anti-Ca ${ }^{2+}$ channel (P/Q-type, $\alpha-1 \mathrm{~A}$ subunit) antibody (red) to show VDCCs and $\alpha$ BTX (green) (O-Q), with fluorescently labeled Fasciculin II (FascII; red) to show AChE and $\alpha$-BTX (green) (R-T). Arrowheads indicate patchy accumulation of vesicles and asterisks faint $\mathrm{AChV}$ staining within the synapse. Bars are $10 \mu \mathrm{m}$.

Figure 5. Misexpression of collagen XIII results in disrupted synaptic adhesion in $\mathrm{Coll3a1}^{\mathrm{oe}}$ mice

(A-B) Electron microscopy of NMJs in the diaphragm of wild-type (+/+) and Coll3al ${ }^{\text {oe }}(\mathrm{oe})$ mice at 12 weeks of age (A) and a magnified insert of ${\text { Coll } 3 a l^{\text {oe }}}_{(B)}$. ShCs are pseudocolored in blue, presynaptic motoneuron termini in purple and the muscle in green. Red 
circles indicate AZs, arrows neurodegenerative multilamellar inclusions inside nerve termini, arrowheads ShC invagination and the asterisk an area without an alignment partner. Bars are $1 \mu \mathrm{m}$. (C-D) Quantification of AChV numbers per $\mu \mathrm{m}^{2}$ (C) and AZ numbers per $\mu \mathrm{m}$ (D). $\mathrm{N}(\mathrm{wt} ; \mathrm{oe}):(4 ; 4)$ and $\mathrm{n}$ (total number of synapses in wt;oe): $(7 ; 7, \mathrm{~B}),(10 ; 8, \mathrm{C})$. The data is presented NMJ-wise. Unpaired t-test, two-tailed: $\mathrm{p}=0.74$ (B) and $\mathrm{p}=0.65$ (C). ns=not significant.

Figure 6. Electrophysiological recordings indicate an altered RRP of vesicles thus compromising long-lasting repetitive evoked $\mathrm{NMJ}$ function in $\mathrm{Coll3a1}^{\mathrm{oe}}$ mice

(A-I) Electrophysiological measurements in the diaphragm of wild-type (wt) and Coll3al ${ }^{\text {oe }}$ (oe) mice at 16 to 20 weeks of age. (A-C) Representative trace of the spontaneous MEPP (A) and quantification of the spontaneous MEPP amplitude (B) and frequency (C). N(wt;oe): (9;10). Mann-Whitney test, two-tailed: exact $\mathrm{p}=0.45$ (B) and unpaired t-test, two-tailed: $\mathrm{p}=0.76$ (C). (D-E) Measurements of the sucrose-induced MEPP frequency (D) and representative traces $(\mathrm{E}) . \mathrm{N}(\mathrm{wt} ; \mathrm{oe}):(9 ; 10)$. Unpaired t-test, two-tailed: $\mathrm{p}=0.02$. (F-G) Representative traces of evoked (G) and repetitively stimulated (100 repetitive nerve stimulations at $30 \mathrm{~Hz}$ ) EPP amplitudes (F). (G-I) Quantification of the amplitude of the first (G) and $100^{\text {th }}$ peaks of evoked EPP (I). N(wt;oe): $(8 ; 8, \mathrm{G})$ and $(7 ; 7, \mathrm{I})$. Unpaired t-test, twotailed: $\mathrm{p}=0.18(\mathrm{H})$ and unpaired t-test, two-tailed: $\mathrm{p} \leq 0.001$ (I). ${ }^{*} \mathrm{p}<0.05,{ }^{*} * \mathrm{p}<0.001$, ns $=$ not significant.

Figure 7. Extrasynaptic exogenous collagen XIII primarily locates at the MTJ and fascial fibroblasts in $\mathrm{Coll3a1}^{\mathrm{oe}}$ mice

(A-C) Co-staining for collagen XIII (ColXIII; red) and fast myosin heavy chains (fMHC; blue) in the diaphragm (DIA, A), soleus (SOL, B) and EDL muscle (C) of wild-type (+/+), ${\text { Coll } 3 a 1^{\text {oe }} \text { (oe) and Coll3al }}^{-/-}(-/-)$mice at 12 weeks of age. The images were taken at the insertion of the soleus and EDL and at the muscle fiber ends towards the central tendon in the 
diaphragm. Muscle fibers are picked out with white dashed lines. Arrows indicate diffuse collagen XIII staining at the end of the muscle fibers and arrowheads frizzled collagen XIII staining in the tendons. (D-F) Staining with the anti-HA-tag antibody to show exogenous collagen XIII in the diaphragm (D), soleus (E) and EDL (F) of wild-type (D-E) and Coll3al ${ }^{\text {oe }}$ mice (D-F) at 12 weeks of age. (G) Co-staining for collagen XIII (ColXIII; red) and fast myosin heavy chains (fMHC; blue) in the diaphragm of wild-type $(+/+)$, Coll $_{3} \mathrm{al}^{\mathrm{oe}}$ (oe) and $\mathrm{Coll}_{3} \mathrm{al}^{-/-}(-/-)$mice at 12 weeks of age. Arrows indicate examples of scattered collagen XIII staining and the Z-projection shows the whole width of the diaphragm muscle. (H) Immunostaining for the HA-tag in the diaphragm of wild-type and $\mathrm{Coll}_{3 a l^{\mathrm{oe}}}$ mice at 12 weeks of age. Bars are $20 \mu \mathrm{m}$. (I-J) Triple-staining with DAPI (blue) to show nuclei, the antiHA-tag antibody and an anti-platelet endothelial cell adhesion molecule (PECAM-1; green) antibody to show endothelial structures (I), or an anti-alpha smooth muscle actin ( $\alpha$-SMA; green) to show myofibroblasts (J). Arrows indicate HA-tag immunoreactivity in the cytoplasm/at the plasma membrane/at the cell periphery. Arrowheads indicate $\alpha$-SMA immunoreactivity adjacent to the HA-tag staining, possibly indicating that the HA-tagpositive cells are activated fibroblasts. Bars are $10 \mu \mathrm{m}$.

Figure 8. Overexpression of collagen XIII leads to reduced growth and aberrant muscle morphology in $\operatorname{Coll3a1}^{\mathrm{oe}}$ mice

(A-B) Body weight measures for wild-type (+/+) and Coll3al ${ }^{\mathrm{oe}}$ (oe) female from 2 to 75 weeks (wk) of age (A) and male from 4 to 75 weeks of age (B). N(wt female;oe felame): 2 wk (6;6), 4 wk (6;11), 12 wk (10;12), 25 wk $(6 ; 14), 35$ wk $(6 ; 7)$ and 75 wk (7;6). Unpaired ttest, two-tailed: 4 wk $\mathrm{p}=0.04,25$ wk $\mathrm{p}=0.03,35$ wk $\mathrm{p}=0.02$ and 75 wk $\mathrm{p}=0.01$. MannWhitney, two-tailed: 2 wk p=0.002 and 12 wk p=0.03. $\mathrm{N}($ wt male;oe male): 4 wk $(8 ; 11), 12$ wk $(13 ; 12), 25$ wk $(14 ; 7), 35$ wk $(4 ; 10)$ and 75 wk $(8 ; 10)$. Unpaired t-test, two-tailed: 4 wk $\mathrm{p}=0.02,12$ wk $\mathrm{p}=0.01,25$ wk $\mathrm{p}=0.04$. Mann-Whitney, two-tailed: 35 wk $\mathrm{p}=0.31$ and 75 wk 
$\mathrm{p}=0.01$. (C-E) Muscle weight of the diaphragm (DIA, C), soleus (SOL, D) and EDL (E) normalized by reference to body weight (bw) at 4 and 12 weeks of age; the muscle weight/body weight ratio of wild-type mice is defined as $100 \%$. N(4 wk;12 wk); wild-type

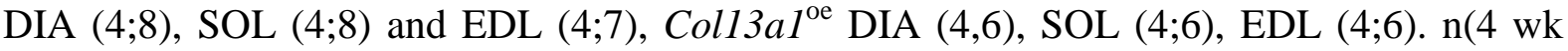

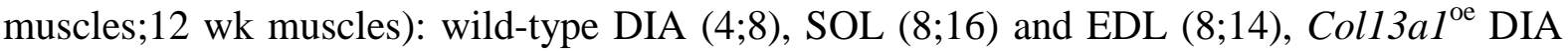
$(4 ; 6)$, SOL $(7 ; 11)$ and EDL $(7 ; 12)$. Unpaired t-test, two-tailed: DIA 4 wk p=0.03, 12 wk $\mathrm{p}=0.0007$, SOL 4 wk $\mathrm{p}=0.71,12$ wk $\mathrm{p}<0.0001$, and EDL 4 wk $\mathrm{p}=0.66$ and 12 wk $\mathrm{p}=0.66$. The data is calculated muscle-wise. (F-H) Histology of the diaphragm (DIA, F), soleus (SOL, G) and EDL (H) in wild-type (+/+) and Col13al ${ }^{\mathrm{oe}}$ mice (oe) at 12 weeks of age. Bars are $50 \mu \mathrm{m}$. (I-K) Quantification of the muscle fiber size ratios after dividing the fibers into three size

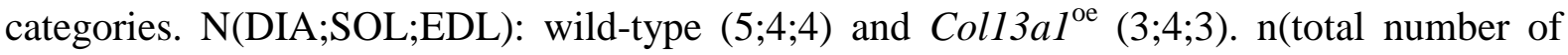
calculated fibers in DIA;SOL;EDL): wild-type $(539 ; 297 ; 304)$ and Col13al $^{\text {oe }}(262 ; 268 ; 235)$. Mann-Whitney, two-tailed: DIA fibers sized $<500 \mu \mathrm{m}^{2} \mathrm{p}=0.04$, fibers sized $500-1000 \mu \mathrm{m}^{2}$ $\mathrm{p}=0.04$ and fibers sized $>1000 \mu \mathrm{m}^{2} \mathrm{p}=0.57(\mathrm{I})$, SOL fibers sized $<1000 \mu \mathrm{m}^{2} \mathrm{p}=0.11$, fibers sized $1000-1500 \mu \mathrm{m}^{2} \mathrm{p}=0.49$ and fibers sized $>1500 \mu \mathrm{m}^{2} \mathrm{p}=0.69(\mathrm{~J})$, EDL fibers sized $<1000 \mu \mathrm{m}^{2} \mathrm{p}=0.40$, fibers sized $1000-2000 \mu \mathrm{m}^{2} \mathrm{p}=0.40$ and fibers sized $>2000-\mu \mathrm{m}^{2} \mathrm{p}=0.28$ (K). ${ }^{*} \mathrm{p}<0.05, * * \mathrm{p}<0.01 * * *, \mathrm{p}<0.001, \mathrm{~ns}=$ not significant.

Figure 9. Overexpression of collagen XIII leads to dysmorphic nerve and AChR cluster patterns in $\mathrm{Coll3a1}^{\mathrm{oe}}$ mice

(A) Stereomicroscope images of fresh, right hemidiaphragms of wild-type $(+/+)$ and

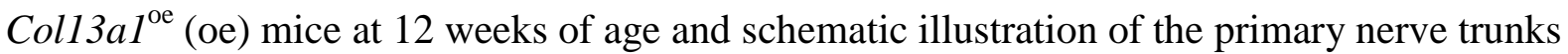
and secondary branches (black) assessed from stereomicroscope images. Red lines indicate the lengths of secondary branches calculated as the distances of their tips from the main nerve trunk. Green line indicates the length of the hemidiaphragm used to normalize the nerve lengths. (B-C) Quantification of the secondary branch length (B), normalized by reference to 
the hemidiaphragm length, and number of secondary branches (C) in the right hemidiaphragm of wild-type $(+/+)$ and $\operatorname{Coll}_{3 a l^{\text {oe }}}(\mathrm{oe})$ mice at 12 weeks of age. N(wt;oe): (6;7). Unpaired t-test, two-tailed: branch length $\mathrm{p}=0.01$ (B) and branch number $\mathrm{p}=0.001$ (C). (D) Stereomicroscope images of the whole diaphragm freshly stained with endogenous AChE activity in dark brown. Arrowheads indicate the edges of sites with AChE activity. (E) Quantification of the width of AChE-positive NMJ patterns normalized by reference to the hemidiaphragm length. N(wt;oe): (6;4). Mann-Whitney test: exact p=0.01. (F) Quantification of the average hemidiaphragm length. The mean hemidiaphragm length in the wild-type muscles is defined as $100 \%$ in artificial units. $\mathrm{N}(\mathrm{wt} ; \mathrm{oe})$ : $(7 ; 6)$. Unpaired t-test, two-tailed: $\mathrm{p}=0.03 . * \mathrm{p}<0.05, * * \mathrm{p}<0.01, * * * \mathrm{p}<0.001$. (G) Immunofluorescent images of the anterior right hemidiaphragm stained with $\alpha$-BTX (red) in wild-type and $C o l 13 a 1^{\text {oe }}$ mice at 12 weeks of age. Arrowheads indicate rear locations for AChR clusters. The bar is $1000 \mu \mathrm{m}$. (H) Immunofluorescent images of the anterior right hemidiaphragm stained with $\alpha$-BTX (red) in wild-type and Coll3al ${ }^{\mathrm{oe}}$ mice at E17.5. The bar is $100 \mu \mathrm{m}$. (I) Co-labeling of the diaphragm in wild-type and $\mathrm{Coll}_{3 a l^{\mathrm{oe}}}$ mice at E17.5 with the anti-collagen XIII antibody (ColXIII; red) and $\alpha$-BTX (green). Arrowheads indicate collagen XIII immunoreactivity in the AChRpositive areas and arrows collagen XIII accumulation in cell-like structures. (J) Co-labeling of the diaphragm in wild-type and Coll3al ${ }^{\mathrm{oe}}$ mice at E17.5 with the anti-HA-tag-antibody (HA-tag; red) to show exogenous collagen XIII immunoreactivity and $\alpha$-BTX (green). Arrows as in J. Bars are $10 \mu \mathrm{m}$.

This article is protected by copyright. All rights reserved. 

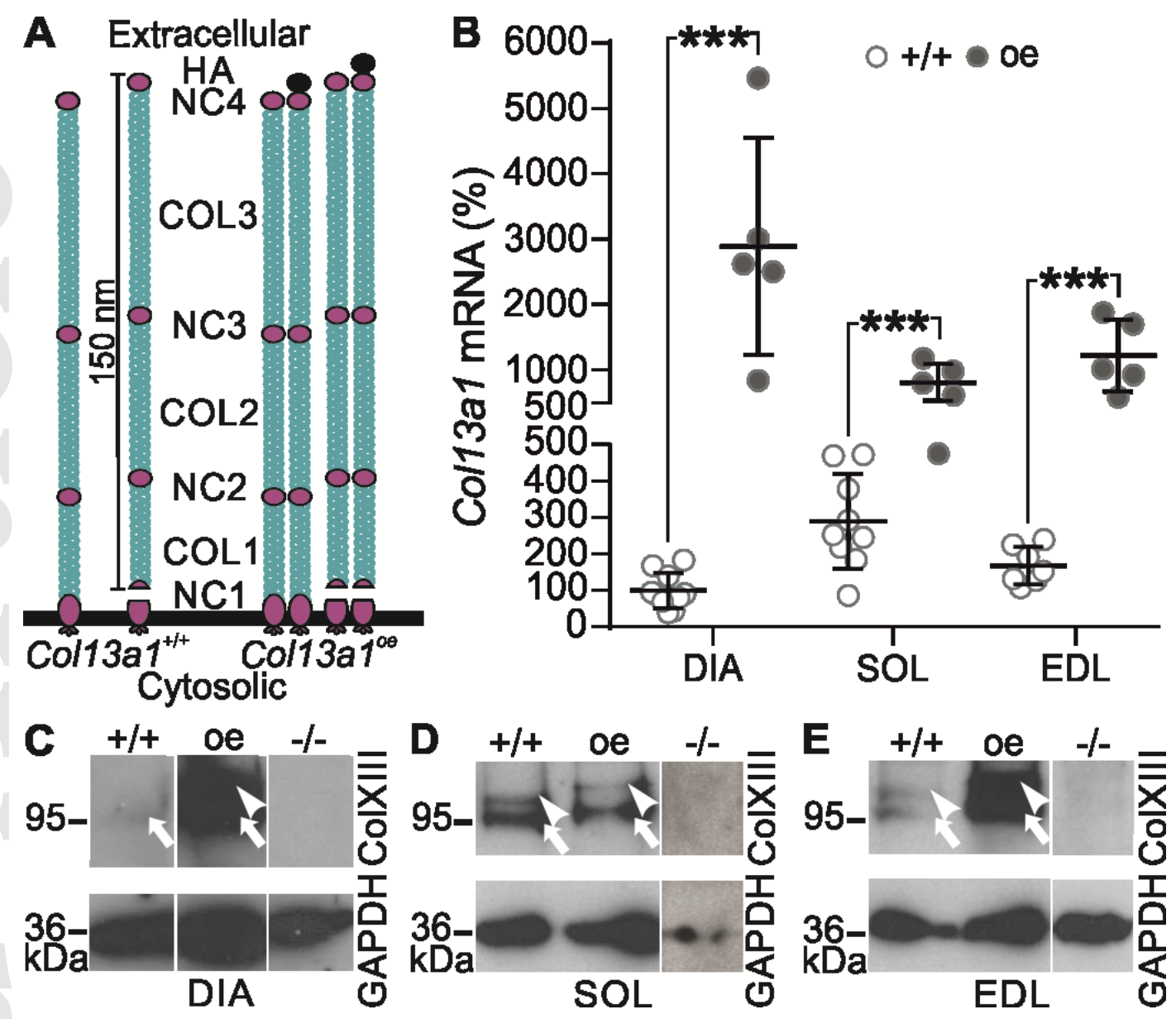


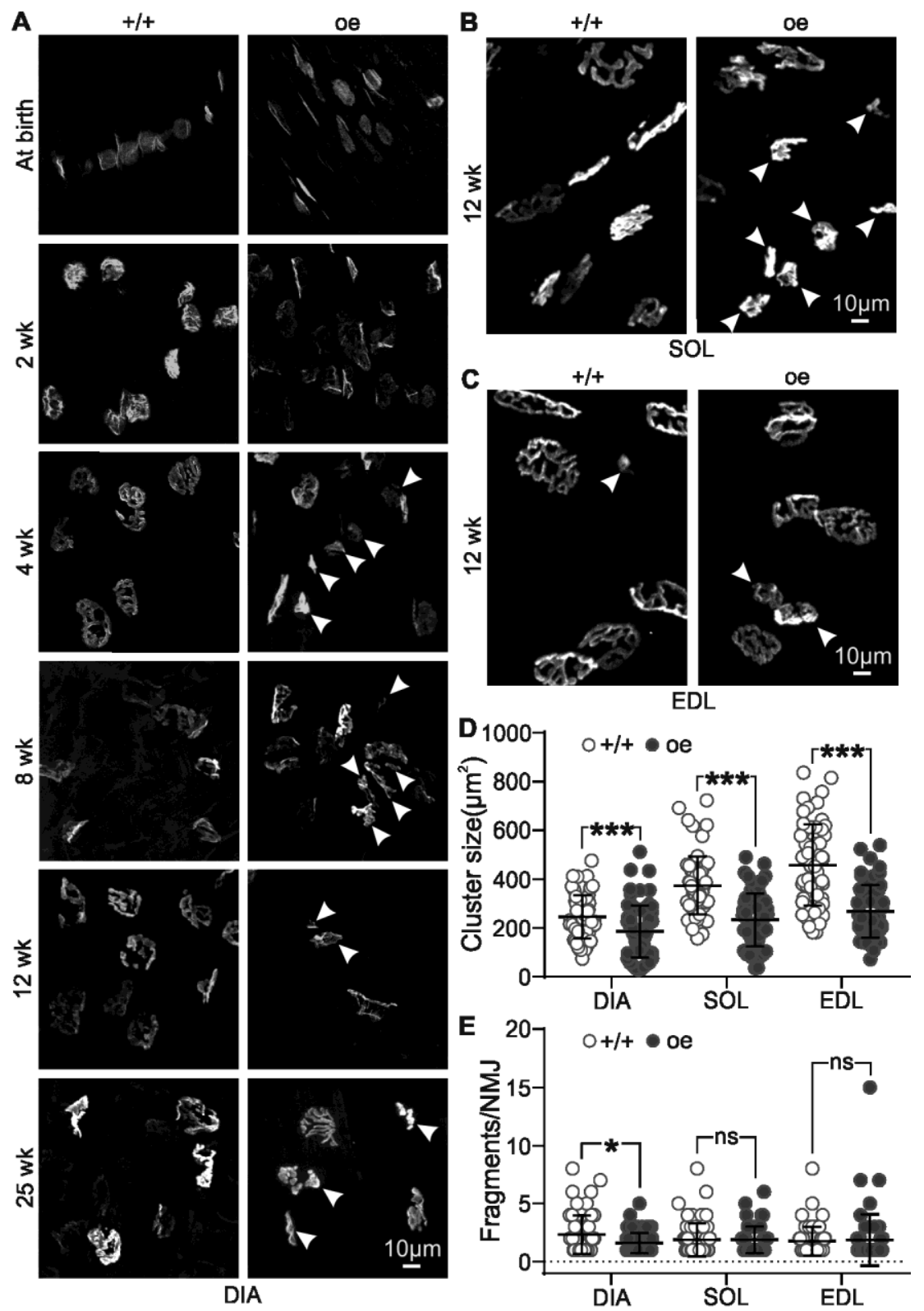

This article is protected by copyright. All rights reserved. 


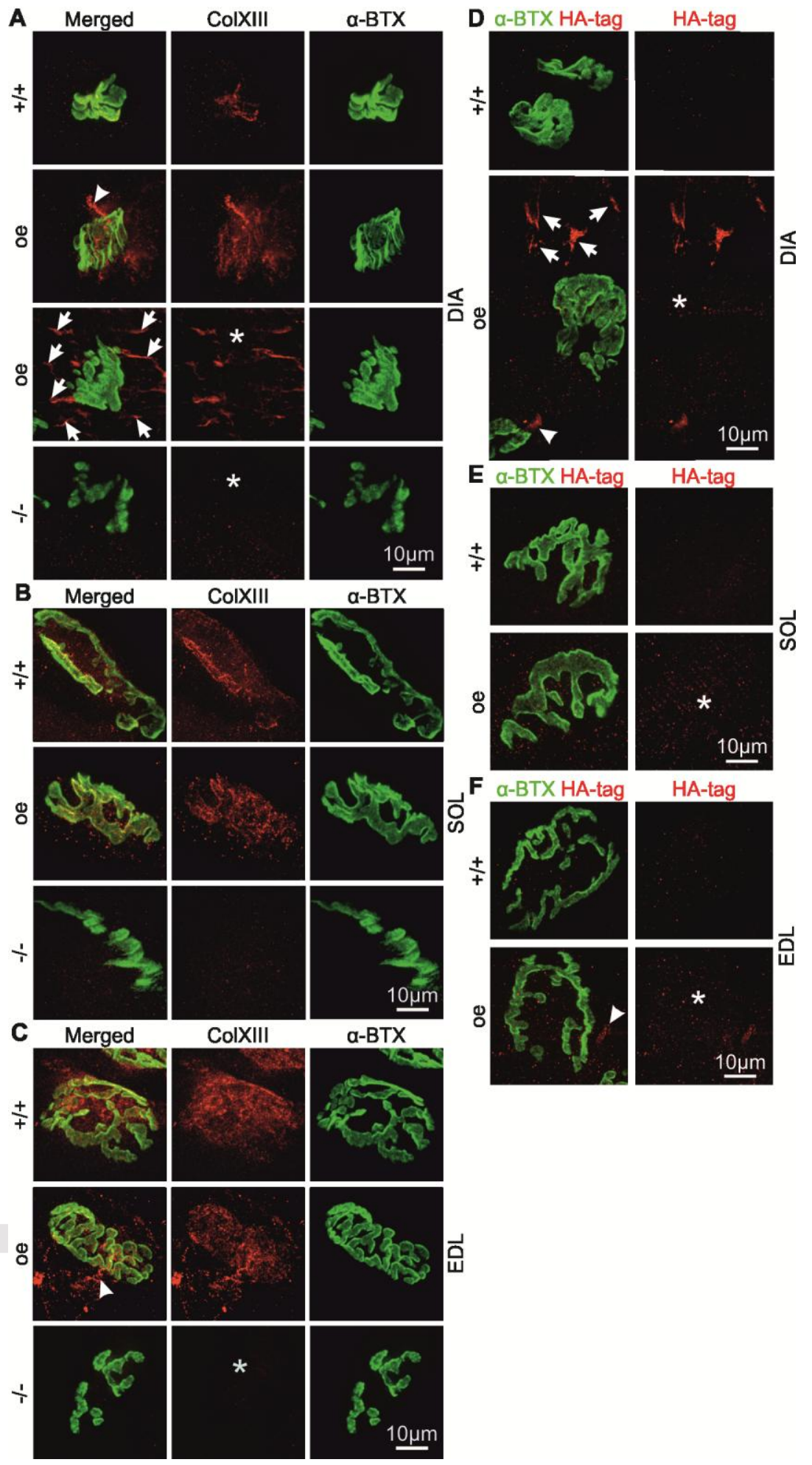

This article is protected by copyright. All rights reserved. 


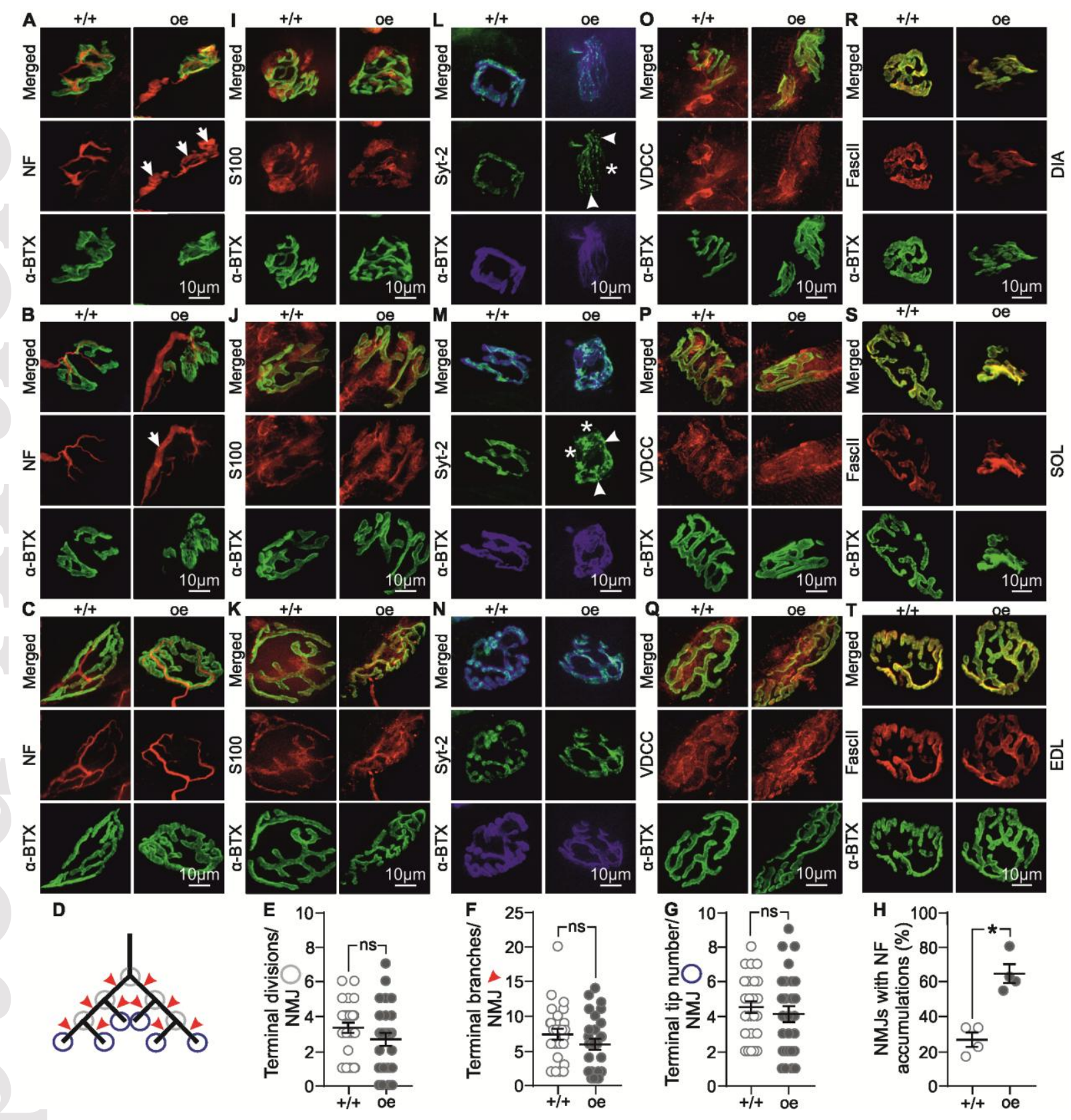

This article is protected by copyright. All rights reserved. 


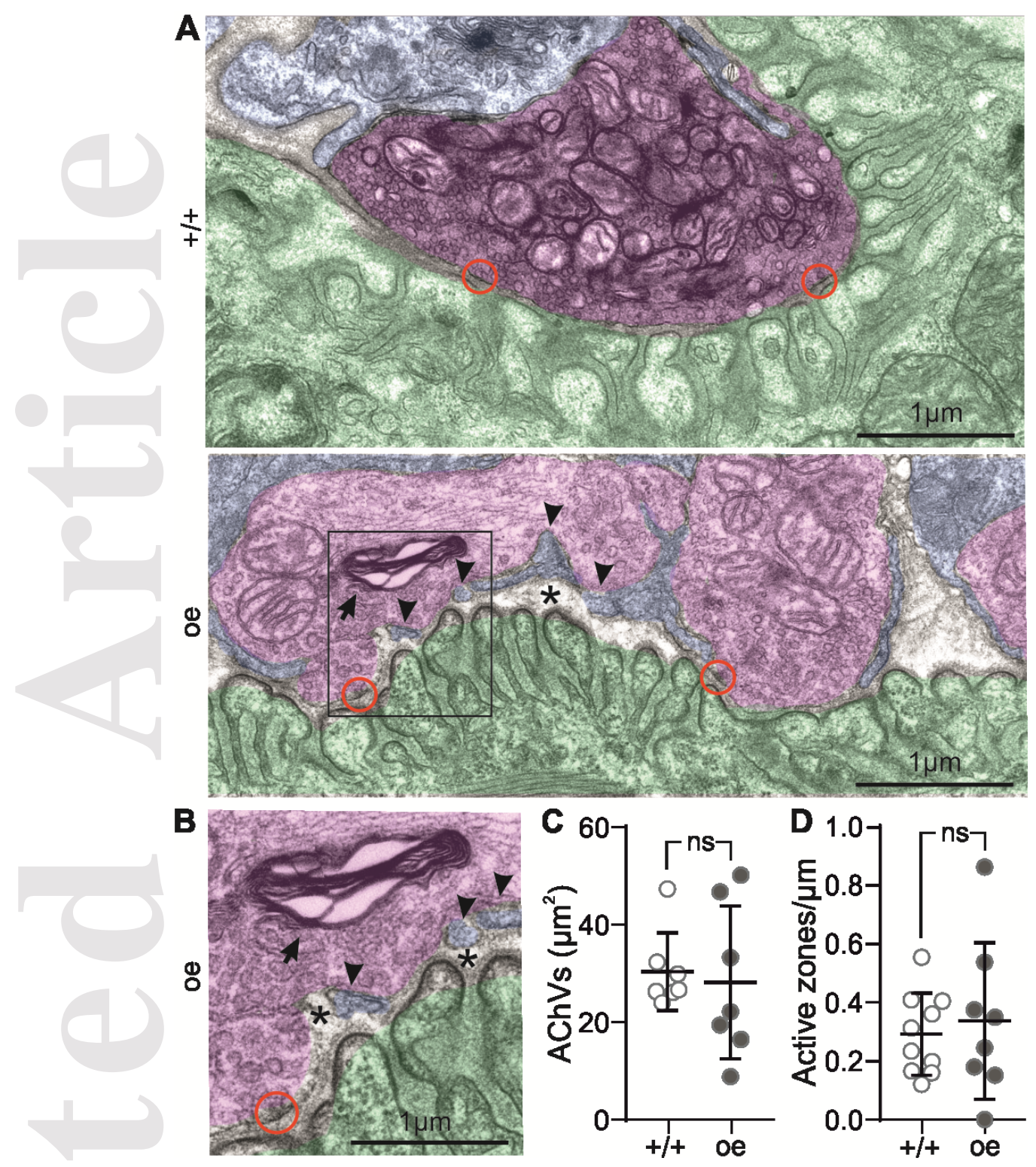

This article is protected by copyright. All rights reserved. 

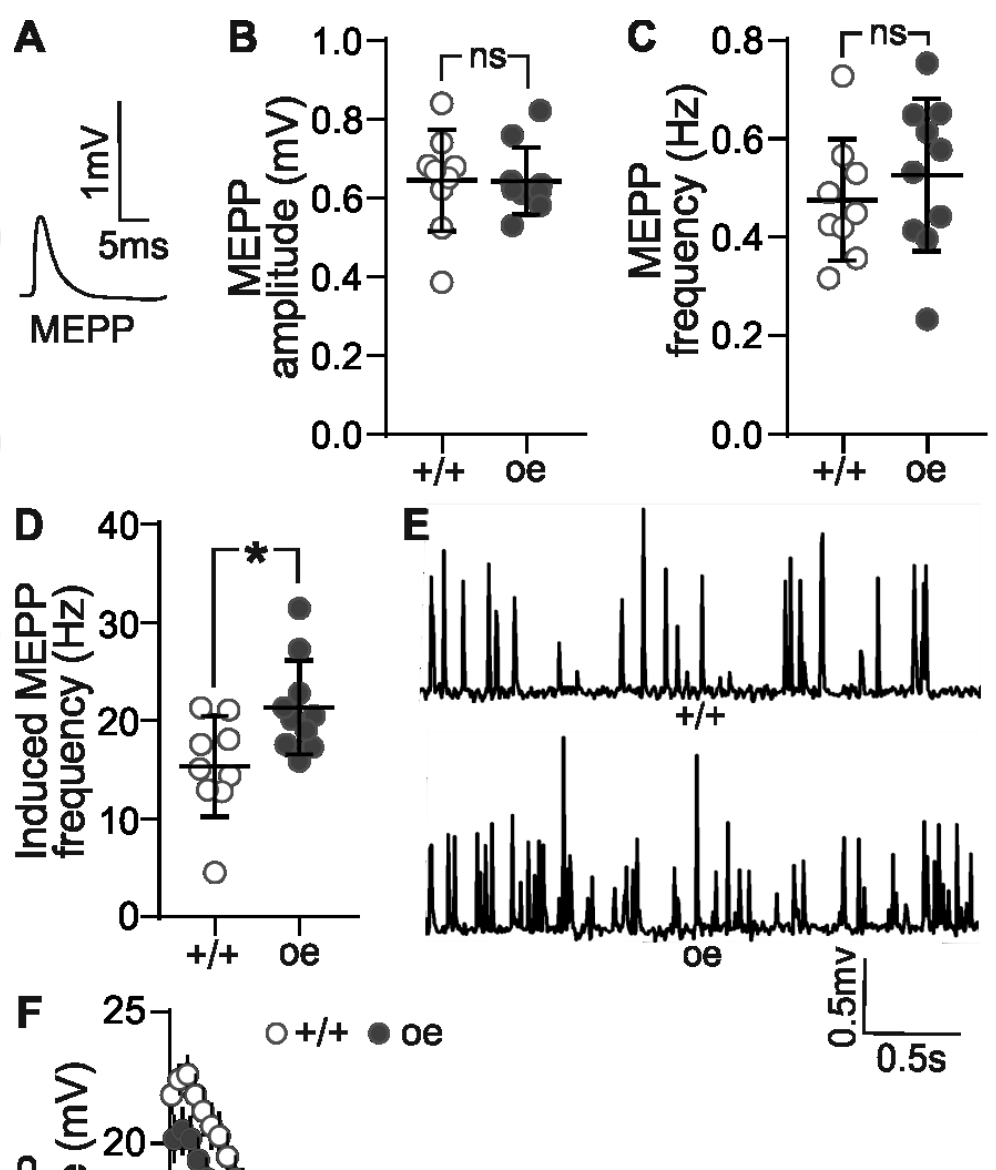

온은
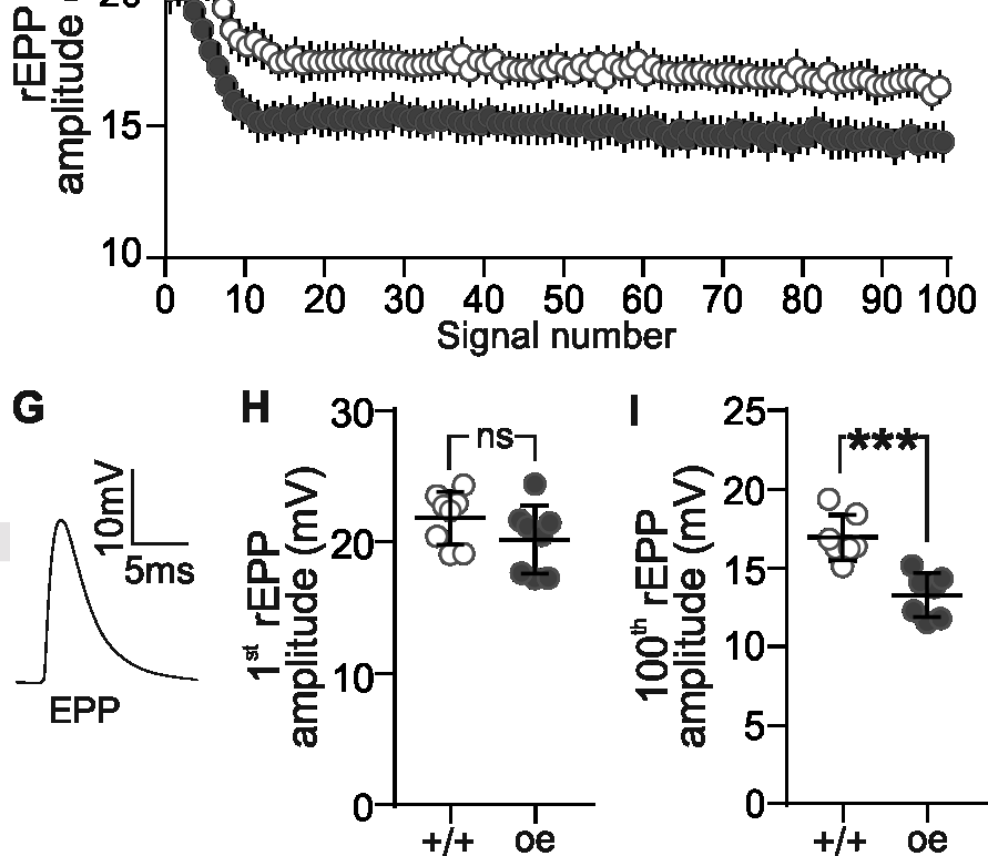


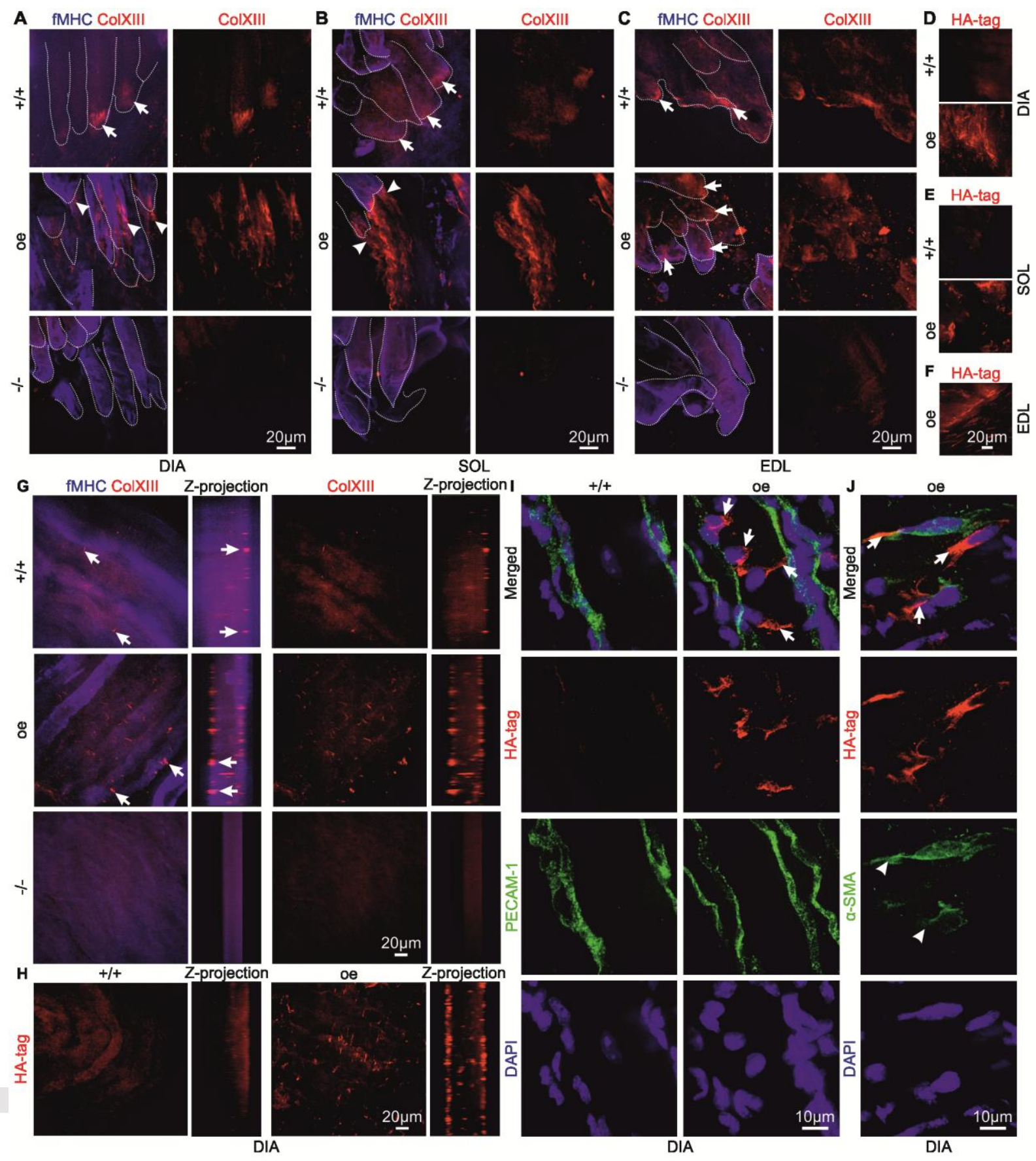

This article is protected by copyright. All rights reserved. 

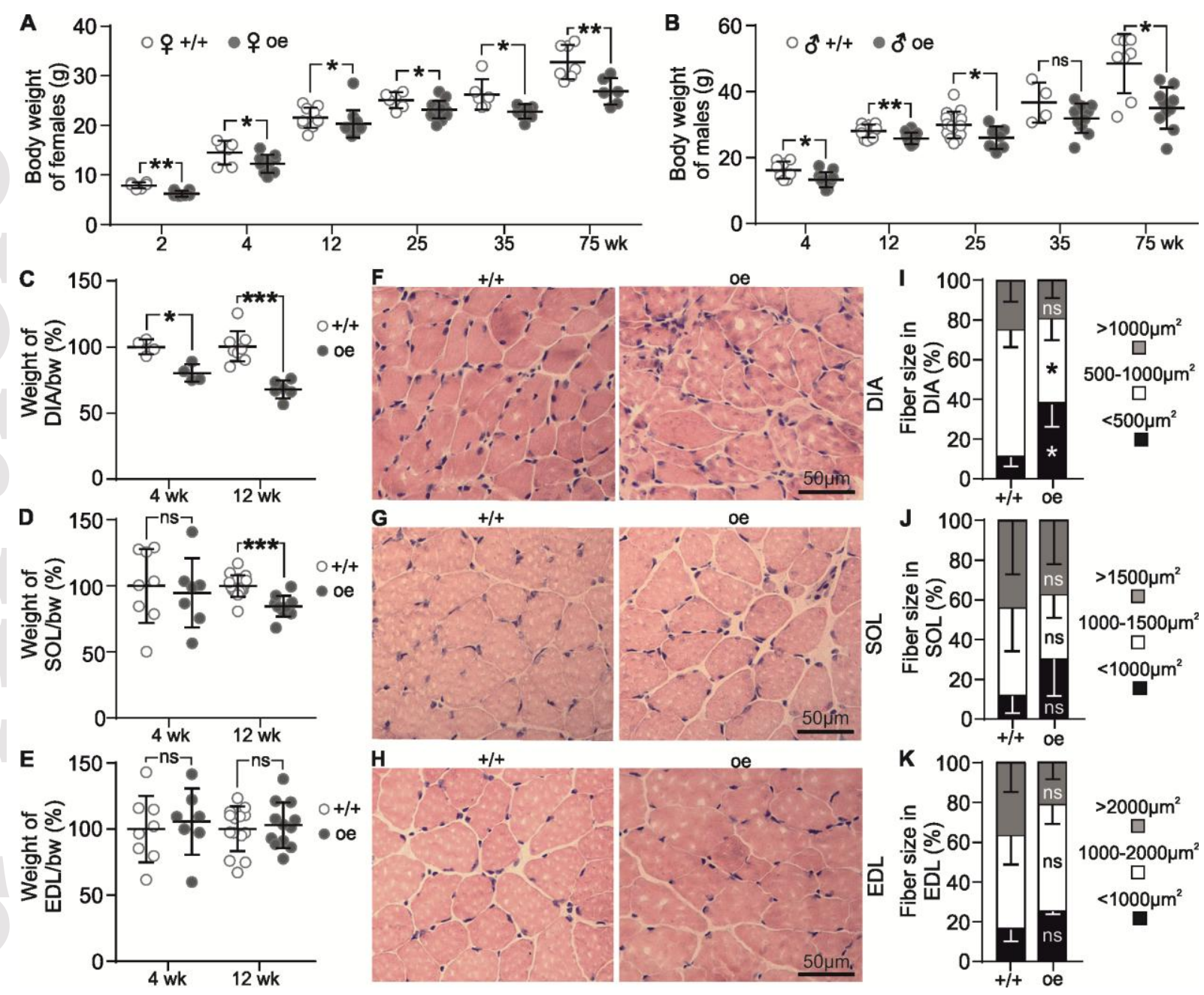

This article is protected by copyright. All rights reserved. 


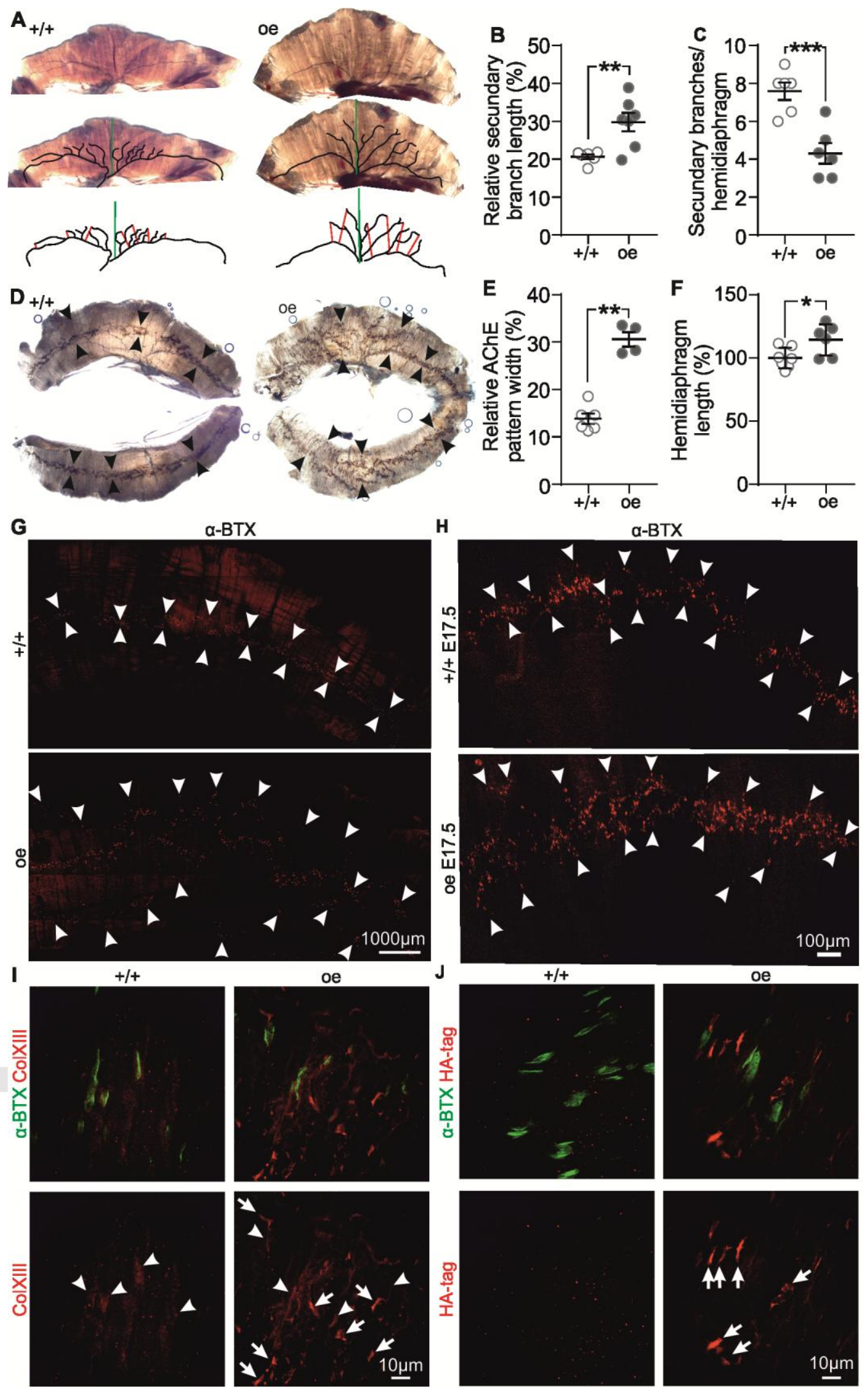

This article is protected by copyright. All rights reserved. 